\title{
Title: ROR2 blockade as a therapy for osteoarthritis
}

\section{Single Sentence Summary}

ROR2 blockade improves the functional and structural outcomes of osteoarthritis in preclinical animal models by inhibiting YAP signaling.

\section{Authors}

Anne-Sophie Thorup ${ }^{1 *}$, Danielle Strachan ${ }^{1}$, Sara Caxaria ${ }^{1}$, Blandine Poulet $^{2}$, Bethan L. Thomas ${ }^{1}$,

Suzanne E. Eldridge ${ }^{1}$, Giovanna Nalesso ${ }^{3}$, James R. Whiteford ${ }^{1}$, Costantino Pitzalis ${ }^{1}$, Thomas

Aigner $^{4}$, Roger Corder $^{1}$, Jessica Bertrand ${ }^{5}$ and Francesco Dell'Accio ${ }^{1 *}$.

\section{Affiliations}

${ }^{1}$ William Harvey Research Institute, Barts and the London School of Medicine and Dentistry, Queen Mary University of London, London, UK, EC1M 6BQ.

${ }^{2}$ Institute of Ageing and Chronic Disease, University of Liverpool, Liverpool, UK, L7 8TX.

${ }^{3}$ Department of Veterinary Pre-Clinical Sciences, School of Veterinary Medicine, Faculty of Health and Medical Sciences, University of Surrey, Guildford, UK, GU2 7AL.

${ }^{4}$ Institute of Pathology, Medical Center Coburg, Ketschendorferstrasse 33, 96450 Coburg, Germany.

${ }^{5}$ Department of Orthopaedic Surgery, Otto-von-Guericke University, 39120, Magdeburg, Germany.

*Corresponding author. Email: asthorup@gmail.com (A.-S.T.) or f.dellaccio@ gmail.com (F.D.) Overline: OSTEOARTHRITIS 


\section{Abstract}

Osteoarthritis is characterized by the loss of articular cartilage, bone remodeling, pain and disability. No pharmacological intervention can currently halt progression of osteoarthritis. Here we show that blocking receptor tyrosine kinase like orphan receptor 2 (ROR2) improves cartilage integrity and pain in osteoarthritis models by inhibiting yes associated protein (YAP) signaling. ROR2 was upregulated in cartilage in response to inflammatory cytokines and mechanical stress. The main ligand for ROR2, WNT5A, and the targets YAP and connective tissue growth factor (CTGF) were upregulated in osteoarthritis in humans. In vitro, ROR2 overexpression inhibited chondrocytic differentiation. Conversely, ROR2 blockade triggered chondrogenic differentiation of $\mathrm{C} 3 \mathrm{H} 10 \mathrm{~T}^{1} / 2$ cells and suppressed the expression of the cartilage degrading enzymes a disintegrin and metalloproteinase with thrombospondin motifs

(ADAMTS)-4 and -5. The chondrogenic effect of ROR2 blockade in cartilage was independent of WNT signaling and was mediated by downregulation of YAP signaling. ROR2 signaling induced G-protein and Rho-dependent nuclear accumulation of YAP and YAP inhibition was required but not sufficient for ROR2 blockade-induced chondrogenesis. ROR2 silencing protected mice from instability-induced osteoarthritis with improved structural outcomes, sustained pain relief, and without apparent side effects or organ toxicity. Finally, ROR2 silencing in human articular chondrocytes transplanted in nude mice led to the formation of cartilage organoids with more and better-differentiated extracellular matrix, suggesting that the anabolic effect of ROR2 blockade is conserved in humans. Thus, ROR2 blockade is efficacious and welltolerated in preclinical animal models of osteoarthritis. 


\section{Introduction}

Osteoarthritis is a joint disease characterized by breakdown of the articular cartilage (the tissue that covers the ends of the long bones allowing frictionless joint motion) and bone changes including thickening of the bone supporting the cartilage and excessive bone formation at the margins of the joint (osteophytes). Osteoarthritis affects up to a third of the population over the age of 45 (1), is the main cause of chronic disability worldwide, and costs between 1 and $2 \%$ of the gross domestic product in westernized countries (2-5). Osteoarthritis is caused by pathological chronic mechanical injury due to excessive body weight, joint malalignment or joint instability that may be a consequence of lesions to ligaments and menisci. Low-degree inflammation is sometimes present in osteoarthritic joints as a result of tissue damage but is not a major driver of disease progression.

Chondrocytes, the only type of cell present in the cartilage, produce a glycosaminoglycan (GAG)-rich extracellular matrix (ECM), which confers the tissue its biomechanical properties. In resting conditions, the ECM has an extremely low turnover (6). After injury, however, homeostatic mechanisms are deployed, which include upregulation of the cartilage transcription factor SRY-box transcription factor 9 (SOX9) and of its transcriptional targets COL2A1 and $A C A N$, encoding for the major ECM components collagen type II and aggrecan. Small cartilage lesions can heal, albeit often incompletely $(7,8)$, however when the injury is too severe and/or persists, the homeostatic response becomes insufficient. Further ECM remodeling takes place through coordinated matrix synthesis and degradation, the latter driven by the activation of matrix metalloproteinases and aggrecanases (9-11).

Genetic studies in humans and mice have linked mutations leading to excessive activation of canonical WNT signaling to osteoarthritis development (12-17). WNTs are a family of 19 
pleiotropic morphogens that, after binding to Frizzled (FZD) receptors, can signal through multiple pathways classified as $\beta$-catenin dependent or independent. In the $\beta$-catenin-dependent canonical pathway, WNT ligands engage with FZDs and the co-receptors lipoprotein-related protein receptors (LRP)-5 or LRP-6. $\beta$-catenin accumulates in the cytoplasm and translocates to the nucleus, binds to T-cell factor (TCF)/lymphoid enhancer factor (LEF) transcription factors, and activates the transcription of cell-specific target genes. WNT/ $\beta$-catenin-independent pathways are characterized by dimerization of FZDs with different co-receptors. One of these, the planar cell polarity (PCP) pathway, requires the co-receptor ROR2 to be activated $(18,19)$, leading to the phosphorylation of the intracellular molecule Van Gogh-like 2 (VANGL2) (18) and ultimately the suppression of canonical WNT signaling. ROR1, a closely related receptor, modulates other signaling pathways including the Hippo pathway. The Hippo pathway regulates cell growth and organ size and differentiation. Stimuli (such as mechanical) activating the Hippo pathway result in the inhibition of the YAP/tafazzin (TAZ) transcriptional co-activators through direct phosphorylation, ubiquitination and degradation. Inhibition of the Hippo pathway results in accumulation of YAP/TAZ, their translocation to the nucleus, where they bind to TEA domain transcription factor (TEAD) and promote target gene transcription (20). Targets of the RORYAP cascade include WNT5A and CTGF (21).

Excessive activation of $\mathrm{WNT} / \beta$ catenin signaling promotes a form of terminal differentiation called chondrocyte hypertrophy (22). During skeletal development, chondrocyte hypertrophy precedes cartilage calcification and ultimately its replacement by bone. Under physiological conditions articular chondrocytes are resistant to hypertrophy. During osteoarthritis however, ectopic hypertrophic differentiation drives cartilage breakdown $(23,24)$. 
During embryonic development, Ror 2 is expressed mainly in the cartilage structures that will persist throughout life including the anterior portion of the ribs and prospective articular cartilage, but also in the growth plate and other organs such as the dermis and the embryonic telencephalon $(25,26)$. Loss of ROR2 during development results in shorter long bones and delayed cartilage calcification, hypertrophy and endochondral bone formation (26). In humans, loss of ROR2 results in recessive Robinow syndrome, a form of dwarfism that is closely phenocopied by ROR2 loss in mice $(27,28)$. Despite the developmental phenotype of skeletal dysplasia, however, subjects with Robinow syndrome do not display postnatal phenotypes. This suggests that, in physiological conditions, the postnatal functions of ROR2 are compensated. Because of the exquisite expression of ROR2 in the articular cartilage and its effects preeminently on cartilage development, in this manuscript we tested whether ROR2 blockade affects cartilage homeostasis during experimental osteoarthritis and cartilage formation.

\section{Results}

\section{ROR2 signaling is upregulated in osteoarthritis}

ROR2 was detected in the most superficial layer of the articular cartilage in mouse embryos at stage 18.5 days post coitum (Fig. 1A). This expression pattern is similar to that described by in situ hybridization (26) and therefore validated our antibody. Postnatally, one week after inducing osteoarthritis by joint destabilization, ROR2 became detectable in the upper third of the articular cartilage (Fig. 1B). Using expression microarrays in patient samples (29), ROR2 was detected in osteoarthritic cartilage as well as in cartilage of patients without osteoarthritis, whereas the main ROR2 ligand, WNT5A (30-33),was more highly expressed in osteoarthritic cartilage and correlated with the expression of the ROR targets YAP and CTGF (21), and inversely with SOX9 
[Fig. 1C and fig. S1, A and D; (29)]. A principal component analysis showed that such parameters were sufficient to separate healthy from osteoarthritic cartilage samples and, whereas WNT5A contributed mostly to principal component one (explaining $55.5 \%$ of variance), ROR 2 contributed mostly to principal component 2 (explaining an additional 18\%; fig. S1, A to C). At protein level, ROR2 was detected in the superficial layer of osteoarthritic cartilage by immunostaining (Fig. 1D) and confirmed by western blotting in cartilage and synovial membrane (Fig. 1E) in human samples.

To better define the temporal dynamics of ROR2 expression in osteoarthritis, we mined microarray data deposited in the GEO database at NCBI [GEO accession GSE41342; (34)]. This analysis revealed an early peak of Ror2 upregulation within the first 2-4 weeks after joint destabilization, possibly associated with post-surgical inflammation (Fig. 1F). The expression patterns of Wnt5a, Yap and Ctgf were similar to that of Ror2 (Fig. 1F). In keeping with inflammation triggering ROR2 expression, the analysis of a publicly available dataset [GEO accession GSE75181; (35)] revealed that exposure of primary human articular chondrocytes to interleukin $1 \beta(\mathrm{IL}-1 \beta)$ resulted in upregulation of ROR2 and WNT5A (Fig. 1G). In accordance with the role of mechanical injury in triggering osteoarthritis, explanting murine femoral head articular cartilage from the subchondral bone, a model of mechanical injury, led to short-term upregulation of ROR2 (Fig. 1, H and I and fig. S2). These data suggest that the WNT5A/ROR2 pathway is activated in osteoarthritis.

\section{ROR2/WNT5A expression correlates with chondrocytic differentiation}

To investigate the role of ROR2 in chondrocyte biology, we first correlated the expression of WNT5A and ROR2 in human chondrocytes and synovial membrane-derived mesenchymal stem 
cells (SM-MSCs) at different stages of differentiation. Serial passaging results in progressive loss of chondrocyte phenotypic markers and in the capacity of these cells to form cartilage in vivo (36). The expression of ROR2 progressively decreased from passage 0 to passage 8 [fig. S3A and B (37)]. Although ROR2 expression did not change with transforming growth factor $\beta$ (TGF- $\beta$ )-induced chondrocytic differentiation of SM-MSCs (38), expression of WNT5A increased sharply in differentiating conditions (fig. S3C and D).

\section{ROR2 gain of function inhibits chondrocytic differentiation}

To investigate if the amount of ROR2 influences the degree of chondrocytic differentiation we performed gain of function studies using a mesenchymal cell line. We tested whether ROR2 overexpression (fig. S4A) modulated the capacity of $\mathrm{C} 3 \mathrm{H} 10 \mathrm{~T}^{1} / 2$ cells to differentiate in response to bone morphogenetic protein 2 [BMP2; (39)]. As expected, BMP2 induced rapid chondrocytic differentiation of $\mathrm{C} 3 \mathrm{H} 10 \mathrm{~T}^{1} / 2$ cells, as assessed by Alcian blue staining. Unexpectedly, ROR2 overexpression inhibited chondrogenic differentiation of $\mathrm{C} 3 \mathrm{H} 10 \mathrm{~T}^{1} / 2$ cells in response to BMP2 (Fig. 2A and B). Even in the absence of exogenous BMP2, ROR2 overexpression reduced the expression of the chondrocytic differentiation markers Col2al and Acan (Fig 2C and D). The bone and fibroblast marker collagen type I (Colla1) and the cartilage hypertrophy marker collagen type $\mathrm{X}(\mathrm{ColX})$ were not significantly regulated (Fig. 2E and F). The cartilage stem cell marker Sox2, normally expressed in the superficial zone cells did not change significantly. ROR2 overexpression upregulated the proliferation marker proliferating cell nuclear antigen (PCNA) (Fig. 2G and H). 


\section{ROR2 loss of function supports chondrocytic differentiation}

We designed small interfering RNA (siRNA) that silenced ROR 2 expression by about $73 \%$ at protein level in vitro (fig. S4B). A short hairpin RNA (shRNA)-lentivirus downregulated ROR2 mRNA by $92 \%$ and protein by $56 \%$ (Fig. $3 \mathrm{~A}$ and fig. S4C). The expression of Rorl did not change, confirming the specificity of RNA interference and that there was no compensation (Fig. 3A). Using either the siRNA or shRNA-lentivirus, ROR2 silencing induced chondrocytic differentiation of $\mathrm{C} 3 \mathrm{H}_{10 \mathrm{~T}} \frac{1}{2} 2$ cells, even without BMP2, as assessed by Alcian blue staining (Fig. 3B and C), and Aggrecan mRNA expression (Fig. 3D). ROR2 silencing inhibited the expression of Col2A1 and of the key cartilage degrading enzymes ADAMTS-4 (9) and ADAMTS-5 (10, 11) (Fig. 3E and F).

\section{ROR2 silencing in vivo improves symptoms and structural features of osteoarthritis}

The anabolic effect of ROR2 blockade and the suppression of key catabolic enzymes prompted us to test whether ROR2 loss of function may be beneficial in osteoarthritis. In vivo, chondrocytes are difficult to target with traditional therapeutics and macromolecules because the articular cartilage is avascular and chondrocytes are encased in a dense, strongly negatively charged ECM $(40,41)$. We used siRNA coupled with atelocollagen as it was previously shown to efficiently target murine cartilage $(42,43)$. In time course and dose-response experiments we established that intra-articular injection of $7 \mu \mathrm{L}$ of $20 \mu \mathrm{M}$ ROR2-siRNA conjugated to $0.5 \%$ atelocollagen (ROR2i) achieved $\sim 50 \%$ reduction of ROR2 protein expression compared to scrambled siRNA for as long as 5 days (Fig. 4A and fig. S5). Importantly, this silencing efficiency was sufficient to downregulate the ROR target CTGF (21) by $\sim 60 \%$ (Fig. 4B and C). 
To assess the efficacy of ROR2i in a model of instability induced osteoarthritis, we subjected skeletally mature mice to menisco-ligament injury [MLI; (44-46)]. Two weeks after surgery, when cartilage lesions are established (47), the mice received bilateral intra-articular injections of either ROR2i or scrambled siRNA (control) every 5 days. After 5 weeks of treatment, half of the mice receiving ROR $2 \mathrm{i}$ were switched to receive scrambled siRNA (crossover group, Fig. 4D). Starting 7 weeks after surgery, the control group developed pain on weight bearing (incapacitance) as measured by the percentage of body weight loaded on each limb (Fig. 4E). Strikingly, the mice receiving ROR2i did not develop pain. The crossover group remained pain-free for additional 3 weeks after treatment was swapped before developing pain, without ever reaching the same pain threshold as the control group (Fig. 4E and F). Twelve weeks after surgery all mice were euthanized. The area under the curve (AUC) for all treatments between week 5 and 12 was higher in the ROR2i group compared to control, whereas the crossover group had an intermediate outcome (Fig. 4G). To validate that the reduction of body weight loaded on the operated limb was due to pain and not due to other factors such as reduced range of movement or muscle weakness, we administered buprenorphine, an opioid analgesic, or saline to mice from the control group which had high incapacitance 12 weeks after surgery. After 1 hour, incapacitance normalized in the group that received buprenorphine but not in the mice that received saline (Fig. 4H), thereby confirming that incapacitance, in this model, measures pain at weight bearing.

ROR2i reduced the degree of structural damage to cartilage as assessed by Osteoarthritis Research Society International (OARSI) score (Fig. 4I and J) and histomorphometric quantification of safranin $\mathrm{O}$ staining (Fig. 4K). The crossover group, again, had an intermediate outcome. As expected, bone density increased in the destabilized knee compared to the 
contralateral, sham-operated, or non-operated knees, however there were no differences between treatments as assessed by micro computed tomography ( $\mu \mathrm{CT}$ ) (fig. S6A) or histomorphometry (fig. S6B). No differences were detected in synovial lining thickness, osteophyte perimeter or area (fig. S6C to E). Importantly, no overt toxicity or differences in body weight between groups were observed throughout the course of treatment (Fig. 4L). ROR2i did not alter liver, kidney, muscle or bone parameters (table S1). Similar results, both in terms of pain and structural outcomes, were obtained in an independent experiment when ROR2i was started four weeks after surgery (fig. S7).

\section{ROR2 silencing supports formation of human cartilage organoids in vivo}

One problem with translating data from murine models to patients is the degree of conservation of molecular pathways across the species. To test whether ROR2 blockade induces cartilage formation in vivo in human chondrocytes we used an established adoptive model (48-50). Human articular chondrocytes transduced with ROR2-shRNA lentivirus and implanted subcutaneously in nude mice formed cartilage organoids that were more differentiated than those obtained from chondrocytes transduced with control shRNA (Fig. 5). This confirms that ROR2 blockade is sufficient to support cartilage differentiation in human chondrocytes obtained from joints with end-stage osteoarthritis in vivo in mice.

\section{Mechanism of action of ROR2 blockade}

In keeping with previous literature, we found that overexpression of ROR2 in HEK293 cells inhibited the capacity of WNT3A to activate canonical WNT signaling as assessed using the SUPER8TOPFlash reporter assay $(51,52)$. As expected, co-stimulation with WNT5A enhanced the capacity of ROR2 to inhibit WNT3A-induced activation of WNT signaling (Fig. 6A). 
Inhibition of the WNT/ $\beta$-catenin branch induced by ROR2 overexpression was confirmed in the mesenchymal cell line C3H10T1² (Fig. 6B). In contrast to HEK293 cells, in C3H10T12/2 cells costimulation with WNT5A had no additional effect. This discrepancy may be due to high Ror2 expression in C3H10T1/2 cells whereas ROR2 mRNA was undetectable in HEK293 cells (fig. S8). Therefore, activation of ROR2 signaling in $\mathrm{C} 3 \mathrm{H} 10 \mathrm{~T}^{1} \frac{1}{2}$ by endogenous WNT5A or other WNTs present in the cell culture medium may be causing the ceiling effect under these experimental conditions, although other differences between the two cell lines in terms of their ROR2 signaling machinery cannot be excluded. ROR2 overexpression did not inhibit the capacity of the glycogen synthase kinase $3 \beta$ (GSK3- $\beta$ ) inhibitor 6-bromoindirubin-3'-oxime (BIO) to activate WNT signaling, thereby suggesting that the inhibitory effect is upstream of GSK3- $\beta$ (53) (Fig. 6C). Unexpectedly, in C3H10T1/2 cells ROR2 silencing did not result in dysregulation and increased activation of canonical WNT signaling by WNT3A (Fig. 6D). For this reason, and because activation of canonical WNT signaling inhibits chondrogenesis (50, 54, 55), de-repression of canonical WNT signaling was unlikely to be responsible for the chondrogenic effect of ROR2 inhibition. The closely related receptor ROR1 was recently shown to regulate the hippo pathway including YAP and its downstream targets Ctgf and Wnt5A (21). Therefore, we sought to understand whether the mechanism of action of ROR2 blockade on chondrogenic differentiation was through regulation of YAP signaling. In keeping with this hypothesis, WNT5A treatment of $\mathrm{C} 3 \mathrm{H} 10 \mathrm{~T}^{1} / 2$ cells increased the proportion of cells with a nuclear YAP staining pattern within 4 hours (Fig. 6E and F and fig. S9A). In addition, ROR2 overexpression in C28/I2 chondrocytes (which do not express ROR2 endogenously) in the presence of WNT5A resulted in an increased proportion of cells with prevalently nuclear YAP staining (Fig. 6G and $\mathrm{H}$ and fig. S9B and C) and in increased intensity of nuclear YAP staining 
(Fig. 6I and fig. S9D). Importantly, the nuclear localization of YAP was inhibited by the $\mathrm{G}_{\mathrm{i} / \mathrm{o}^{-}}$ protein inhibitor pertussis toxin and the Rho inhibitor CT04 (Fig. 6G to I and fig. S9B to D) thereby suggesting that, as previously reported for ROR1 (21), ROR2-mediated YAP activation requires G-protein-coupled receptors and Rho. This mechanism is consistent with the correlation of WNT5A with YAP and CTGF in cartilage from patients with osteoarthritis, with the similar temporal dynamics of Yap, Ctgf, Ror2 and Wnt5A in the destabilization of the medial meniscus (DMM) model, and with our finding that ROR2i caused downregulation of CTGF in the articular cartilage in vivo.

Finally, we investigated whether YAP downregulation is required for the chondrogenic effect of ROR2i. In keeping with this hypothesis, overexpression of constitutively active YAP (S127A YAP) partially reverted the upregulation of Sox9 induced by ROR2 silencing (Fig. 6J). However, inhibiting YAP signaling directly using verteporfin, an inhibitor of the binding of YAP with TEAD, was not sufficient to induce chondrogenesis (Fig. 6K). Taken together, these data indicate that ROR2 regulates YAP through G-proteins and Rho (Fig. 6L), and that YAP inhibition is required for the chondrogenic differentiation induced by ROR2 blockade (fig. S10).

\section{Discussion}

We have shown that in osteoarthritis ROR2 signaling is associated with cartilage breakdown. ROR2 gain of function inhibited chondrocytic differentiation, whereas loss of function promoted chondrogenesis and, in vivo, improved pain and structural outcomes in osteoarthritis models. ROR2i was not associated with systemic or local toxicity. ROR2 blockade did not affect canonical WNT signaling but reduced YAP signaling in a Rho- and G-protein-dependent manner (fig. S10). YAP inhibition was required for the chondrogenic function of ROR2i but was not 
sufficient per se to induce chondrogenesis. The requirement of G-proteins suggests that, as in the case of ROR1 (21), ROR2 requires a G-protein-coupled co-receptor, most likely FZD (21). Similarly, the requirement of Rho in ROR2 signaling has been documented in other contexts including skeletal development $(18,56)$ and Rho was essential for the capacity of ROR1 to upregulate YAP (21). The distinct function of ROR2 makes it a useful targeting opportunity in a highly redundant system such as WNT signaling. Targeting any of the many ligands of ROR2, including WNT3A, -5A, -11 and-16 (18) which are all expressed in cartilage, would likely result in compensation.

In addition to a disease-modifying effect, ROR2 blockade achieved striking and rapid symptomatic relief. This is an important characteristic from the translational point of view, not only because it would result in immediate benefit for patients, but also because it will warrant compliance and ultimately success in clinical trials where pain is usually a primary outcome. The absence of side effects also makes ROR2i stand out compared to other chondrogenic interventions such as BMPs or TGF- $\beta$, which are potent chondrogenic factors but can induce ectopic cartilage and bone formation (57-59) and play a role in several other organs. For instance, activation of TGF- $\beta$ signaling leads to pulmonary fibrosis and a scleroderma-like syndrome (60). Mammalian target of rapamycin (mTOR) inhibition with rapamycin protects mice from osteoarthritis (61), but rapamycin, also used as an anti-cancer drug, has severe side effects. In our study we treated mice for ten weeks without observing any obvious side effects or toxicity, including kidney and liver function tests. Furthermore, patients with recessive Robinow syndrome, who have loss of function mutations to both ROR2 alleles (27), have no overt phenotype which cannot be ascribed to developmental defects. Therefore, no major side effects should be expected by ROR2 blockade in adulthood. Moreover, we show that $\sim 50 \%$ silencing in 
the joint is sufficient to improve outcomes of osteoarthritis, suggesting that the functions of ROR2 that are not compensated by a $50 \%$ reduction are unlikely to result in toxicity. This is an important advantage of targeting ROR2 for osteoarthritis, which, despite being a severe disabling disease, it is not a life-threatening one. Along the same line, the technology we used to block ROR2 signaling in vivo employed two components, siRNA and atelocollagen, which are already used in clinical settings, the former in various diseases (62-64) and the latter as a filler in aesthetic surgery. Although other targeting strategies are possible, such as a ROR2 blocking antibody, atelocollagen-conjugated siRNA proved to be efficient in engaging with its target within cartilage, where the dense, avascular ECM impedes efficient penetration of many synthetic or natural biomolecules $(41,65)$.

Some limitations of this study should be acknowledged. Therapeutically, a treatment regimen of weekly intra-articular injections is unfeasible in patients, therefore we acknowledge that reformulation, for example by stabilizing the siRNA, or slow release methods would be required before ROR2 blockade can be used clinically. In addition, many patients with osteoarthritis have several joints that are affected; to treat such patients, systemic delivery would be preferable. Finally, we validated ROR2i in a model of instability-induced osteoarthritis. Whether ROR2i would be effective in patients whose osteoarthritis is driven by different mechanisms - obesity, or genetic factors - is still to be tested. 


\section{Materials and methods}

\section{Study Design}

The objective of this study was to develop and evaluate ROR2 blockade as a therapy for osteoarthritis. This study consisted of in vitro and in vivo experiments using samples from patients with end-stage osteoarthritis, or C57BL/6 mice that had undergone a surgical osteoarthritis models. Primary cells from patients, C3H10T1/2 (ATCC), HEK293 cells (ATCC) or C28/I2 (66) were used for in vitro experiments. When melting curves in the real-time PCR reaction indicated abnormal/non-specific amplification, the sample was not included in the subsequent analysis. Similarly, when micromasses became detached or broken during processing/staining, they were removed from analysis. ROR2 expression in osteoarthritis was observed before controlled laboratory experiments were carried out to assess the impact of gain or loss of ROR2. A surgical model of osteoarthritis, the menisco-ligament injury model, was performed in mice. Treatment was delivered using atelocollagen-conjugated siRNA (scrambledor ROR2-siRNA). Animal sample size was calculated on the basis of a small-scale MLI study. Mice were randomly allocated to treatment groups (control, ROR2i or crossover) across cages. Health scores were monitored every 5 days from start of treatment and incapacitance was measured throughout the study. The investigators administering intra-articular injections and measuring incapacitance were blinded to the treatment. Safranin O staining was carried out in batches at random, across treatment groups. When cutting, staining, scoring, and conducting histomorphometrical assessments, the investigators were blinded to treatment. Scoring of osteoarthritis severity was conducted by two independent assessors. Due to repeated injections and fighting, some mice developed local inflammation and skin lesions. These were scored 
according to severity (fig. S11, table S2), and mice that had a score above 3 more than once were excluded from analyses. These reactions were independent of treatment group ( 8 control, 5 ROR2i and 7 crossover mice were excluded). Mice with $<3$ intact sections for assessment of osteoarthritis severity were excluded. In fig. S7, one mouse from the control group was identified using Grubb's test for outliers in $\mathrm{R}(\mathrm{P}=0.041 ;(67,68))$, and was removed from analyses because it had not developed osteoarthritis.

\section{Cartilage harvest, chondrocyte isolation and culture}

Adult human articular cartilage and synovial membrane were obtained from femoral condyles following informed consent from four patients undergoing joint replacement for knee osteoarthritis. Individual number of patient samples indicated in figure legends. All procedures were approved by the East London and The City Research Ethics Committee 3 (ethics approval REC N. 07/Q0605/29). Full thickness explants were prepared for histology and scored for features of osteoarthritis as previously described $(50,69)$. Cartilage and synovium lysates from 1 patient were harvested in radioimmunoprecipitation assay buffer (RIPA) at time of dissection and prepared for western blotting. Chondrocytes and SM-MSCs were isolated and expanded in vitro as previously described $(36,38)$. SM-MSCs were differentiated to chondrocytes using 10 ng/ml TGF- $\beta 1$ (R\&D) in micromass culture for 6 days (38).

\section{Micromass culture and Alcian blue staining}

C3H10T $1 / 2$ cells were plated in micromass as previously described $(39,70)$. When indicated, micromasses were cultured with $100 \mathrm{ng} / \mathrm{ml} \mathrm{BMP} 2$ (R\&D) or $7 \mu \mathrm{M}$ Verteporfin (Sigma) or vehicle. After 3 days, micromasses were harvested for real-time PCR gene expression analysis or fixed and whole-mount stained with Alcian blue. Images were acquired at room temperature with 
a Leica DFC295 camera on a dissecting microscope. Alcian blue staining, extraction and quantification was performed as previously described $(49,70)$. Densitometry of the micromasses was measured using ImageJ (71), by placing all images on a single canvas, splitting into hue, saturation, brightness (HSB) stacks and analyzing the "Saturation" stack with the gel tool. The entire micromass was selected for analysis.

\section{Murine femoral hip cap avulsion model}

Murine femoral head articular cartilage was explanted from the bone as described previously (11, 72, 73). From each mouse, one hip cap was immediately embedded in optimal cutting temperature compound (OCT; Tissue-Tek) and frozen, and the contralateral hip cap was rested ex vivo for the indicated time in complete culture medium, before being harvested for immunofluorescence.

\section{Overexpression and siRNA transfection}

Subconfluent cells were transfected with plasmids or siRNA using JetPRIME transfection reagent (PolyPlus), as previously described (49). pEF1a-mRor2WT was a gift from Roel Nusse (Addgene plasmid \# 22613 ; http://n2t.net/addgene:22613 ; RRID:Addgene_22613) (51). pCMV-flag S127A YAP was a gift from Kunliang Guan (Addgene plasmid \# 27370 ; http://n2t.net/addgene:27370 ; RRID:Addgene_27370) (74). An empty vector was used as a negative control, and enhanced green fluorescent protein (eGFP) to monitor transfection efficiency. ROR2 siRNA was synthesized with Ambion Silencer siRNA synthesis kit (Thermo Fisher), and used at a final concentration of $20 \mathrm{nM}$. A scrambled sequence with the same GC content was used as a negative control. BLOCK-iT fluorescent oligo (Thermo Fisher) was used to monitor transfection efficiency. 
ShRNA

Lentiviral ROR2- or control shRNA were used as per manufacturer's instructions (TL502626;

Origene).

\section{Total RNA extraction and real-time PCR}

RNA extraction, reverse transcription and gene expression analysis were performed as previously described (50). Primers are listed in table S3.

\section{SUPER8XTopflash assay}

Cells were co-transfected with SUPER8XTOPFlash TCF/LEF-firefly luciferase reporter plasmid (Kind gift from Dr Muy-Teck Teh), CMV-Renilla luciferase plasmid (Promega) and any other plasmids indicated in figures. 24 hours later, cells were stimulated with $100 \mathrm{ng} / \mathrm{mL}$ recombinant WNT3A (R\&D), $100 \mathrm{ng} / \mathrm{mL}$ recombinant WNT5A (R\&D), $5 \mu \mathrm{M}$ BIO (Sigma) or their respective vehicles for 24 hours before luciferase activity was measured using the Dual Luciferase Reporter assay system (Promega).

\section{Western blot analysis}

Western blots were carried out as described previously (75). Membranes were blocked and antibodies diluted in 3\% nonfat milk/1\% bovine serum albumin/0.01\% Tween 20 in phosphate buffered saline (PBS). Primary antibodies used were mouse anti-ROR2 (deposited to the Developmental Studies Hybridoma Bank (DSHB) by Nusse, R. DSHB Hybridoma Product Ror2), diluted 1:500 and mouse anti- $\beta$-actin (Sigma), diluted 1:5000. Horseradish peroxidase (HRP)-conjugated secondary antibodies (Santa Cruz Biotechnology) were diluted 1:2000. 
Protein expression was quantified by analyzing the densitometry of bands using ImageJ (71), and normalized for $\beta$-actin.

\section{Immunocytochemistry}

For immunofluorescence study, cells were transfected if indicated and then grown on chamber slides (Nunc Lab-Tek, Merck) or 96-well plates. For immunofluorescence study of YAP, cells were serum-starved for 16-24 hours, pre-treated with the Rho inhibitor CT-04 (2 ug/mL, Cytoskeleton Inc), pertussis toxin (Ptx, $100 \mathrm{ng} / \mathrm{mL}$, Sigma) or vehicle for 2 hours if indicated, and then stimulated with recombinant WNT5A (100 ng/mL, R\&D), Lysophosphatidic Acid (LPA, $20 \mu \mathrm{M}$, Santa Cruz Biotechnology) or vehicle for 4 hours. Cells were washed with PBS, fixed and permeabilized with ice-cold methanol and stained as described below.

\section{Indirect immunofluorescence}

Indirect immunofluorescence was performed as previously described (75). For antigen retrieval on paraffin sections, pepsin or proteinase $\mathrm{k}$ digestion were used. The primary anti-ROR2 mouse monoclonal antibody, deposited to the DSHB by Nusse, R. (DSHB Hybridoma Product Ror2), was diluted 1:100, primary anti-YAP (14074S, CST) was diluted 1:100. Primary anti-CTGF was generated and diluted 1:1000. The CTGF antiserum was raised in sheep (Micropharm) against CPGDNDIFESLYYRKMYGDMA (CTGF [329-349]; UniProtKB - P29279 human CTGF) synthesized by Bachem AG. The peptide (96\% purity) was conjugated through N-terminal Cys to carrier protein pre-reacted with $\mathrm{N}$-succinimidyl 4-(4-maleimidophenyl)butyrate following previously described methodologies (76). Isotype-matched non-immune immunoglobulin (IgG) controls were used at the same concentration. Secondary antibodies were cy3-goat anti-mouse antibody (Jackson ImmunoResearch Laboratories) diluted 1:300, donkey anti-sheep Alexa 555 
or donkey anti-rabbit Alexa 555 (Life Technologies) diluted 1:1000. Nuclei were counterstained using 4',6-diamidino-2-phenylindole (dapi) or with fluoroshield mounting medium containing dapi (Merck). Images were acquired using an Olympus BX61 microscope with a fixed exposure using either $10 \times / 0.4,20 \times / 0.7$ or $40 x / 0.85$ objective lenses using Cell-Sense software. Images were enhanced using Adobe Photoshop for better rendering without altering relationship of target to control images. Quantification of staining was performed using ImageJ (71). Images were thresholded without altering relationship of target to control images, and the cartilage was selected as a region of interest based on the Nomarski image. Max-min grey values of the fluorescent image alone were normalized by the area for each image, and the $\operatorname{IgG}$ control was set as baseline. Alternatively, the cell counter plugin was used to quantify the number of cells positive for CTGF within the region of interest and normalized by the total number of cells within this region.

For confocal images, Z-stacks were collected using the 40x objective of a Zeiss LSM510 laser scanning confocal microscope. All confocal image acquisition settings were constant throughout the experiment.

Quantification: for each cell, the ideal plane along the $\mathrm{z}$ axis was chosen as that with the brightest staining and the larger area. The blue and the red channels were enhanced individually for best rendering (this does not affect the measured intensity) so that the entire cell was visible in the red channel. The average intensity of the nuclear YAP staining was measured by drawing the largest circle fitting into the nucleus and noting the average intensity value. The average total staining was obtained by manually contouring the cell and reading the intensity value. The average staining intensity of the brightest part of the cytoplasm was also noted. For the staining pattern, 
cells were classified as having a prevalently nuclear YAP staining if, by toggling the dapi channel off, the nucleus was clearly identified as a hyper-stained area; as prevalently cytoplasmic if the nucleus was clearly identified as a hypo-stained area, and diffused when the area of the nucleus was not identified unless the dapi channel was on. The cells with a prevalently cytoplasmic staining were given a score of 0 , cells with a diffuse staining a score of 1 and cells with a prevalently nuclear staining a score of 2 .

\section{Animals}

All animal procedures were approved by the Local Ethics committee and the UK Home Office (PPL 70/7986). Mice were kept in an approved animal care facility and were housed 6 per cage in standard, individually ventilated cages. C57BL/6 and CD1nu/nu mice were obtained from Charles River.

\section{Atelocollagen-conjugated siRNA in vivo}

An equal volume of atelocollagen (Koken and siRNA were combined by rotation at $4{ }^{\circ} \mathrm{C}$ for 20 minutes as described (42), to final concentrations of $0.5 \%$ atelocollagen and $20 \mu \mathrm{M}$ siRNA. $7 \mu \mathrm{l}$ Atelocollagen-conjugated ROR2- or scrambled-siRNA was injected intra-articularly, bilaterally, while mice were under anesthesia. Mice were euthanized after 5 or 7 days. Femoral condyles

were fixed in $4 \%$ paraformaldehyde in PBS at $\mathrm{pH} 7.4$, decalcified, paraffin embedded, sectioned and used for immunofluorescence staining. All tissues between the menisci and tibial growth plate were harvested for protein expression analysis by western blot. 


\section{Destabilization of the medial meniscus}

Osteoarthritis was induced in 10 week old male C57BL/6 mice by destabilization of the medial meniscus (DMM) as previously described (77). Contralateral knees were sham-operated as internal controls. Mice were euthanized 7 days after surgery.

\section{Menisco-ligament injury}

Osteoarthritis was induced in 10 week old male C57BL/6 mice by menisco-ligament injury (MLI), which consisted of surgical resection of the anterior horn of the medial meniscus and of the medial collateral ligament (44-47). Contralateral knees were sham-operated or unoperated. After 2 or 4 weeks as indicated, mice were injected bilaterally with $7 \mu$ atelocollagen-conjugated siRNA every 5 days. Mice were euthanized 8 or 12 weeks after surgery. Blood was collected by cardiac puncture for serum analysis (MRC Harwell clinical pathology laboratory).

\section{Incapacitance}

Incapacitance was measured throughout the study using a Linton incapacitance meter (45).

Measurements were taken over 3 seconds and 10 readings per mouse were taken at each timepoint. For each mouse, the mean incapacitance was calculated at each time-point. The area under the curve from 35- 81 days after surgery for each mouse was calculated as indicated. To avoid confounding factors such as short-term inflammation caused by the intra-articular injections, measurements were taken at least 48 hours after injection. $0.1 \mathrm{mg} / \mathrm{kg}$ buprenorphine or an equal volume of sterile PBS (vehicle) was injected subcutaneously, and 1 hour later incapacitance was measured again. 


\section{Micro-Ct}

After dissection and fixing in 4\% paraformaldehyde overnight, knee joints were stored in $70 \%$ alcohol and scanned with a Bruker Skyscan 1272 with the following parameters: $40 \mathrm{kV}, 250 \mu \mathrm{A}$, Aluminium $0.5 \mathrm{~mm}$ filter; $0.6^{\circ}$ rotation angle, no frame averaging and an isotropic $4.5 \mu \mathrm{m}$ voxel size. Each dataset was rotated in Dataviewer (Skyscan) to ensure similar orientation and alignment for analysis, as previously described (78). Hand-drawn regions of interests (ROI) of the medial tibial epiphyseal bone fraction were selected in the posterior compartment in CTAn (Skyscan), demarcated by the joint space proximally and distal limits defined by the growth plate. Analysis was achieved using 3D algorithms in CTAn to provide bone volume fraction (BV/TV).

\section{Histological analysis and osteoarthritis scoring}

Knees were prepared for histology as previously described $(75,79)$. All images were taken using the same settings on an Olympus BX61 microscope and osteoarthritis severity was assessed using the OARSI scoring system (80). Histomorphometrical analysis of Safranin O staining, subchondral bone thickness, synovial thickness and osteophytes were carried out as described in supplementary methods, fig. S12.

\section{In vivo ectopic cartilage formation assay}

The ectopic cartilage formation assay was modified from previously described protocols (36, 49, 50). Freshly isolated human articular chondrocytes were transduced with a ROR2- or controlshRNA lentivirus and passaged once. For each injection 1 million transduced chondrocytes were resuspended in $100 \mu \mathrm{L}$ of sterile PBS/ type 1 collagen (Corning) and injected subcutaneously in the back of 3-week-old female CD1nu/nu mice. After two weeks the mice were sacrificed and 
cartilage implants were retrieved. The implants were embedded in OCT and stained with Toluidine Blue for histological analysis (supplementary methods, fig. S13).

\section{Statistical analysis}

All figures show individual data points. Where there are no boxplots, the error bars represent standard error of the means except in figures 4E and S7B where they represent $95 \%$ confidence intervals. Parametric data were compared with student's t-test. For multiple comparisons, analysis of variance (ANOVA) test followed by Tukey's honest significant difference (HSD) post hoc test for multiple comparisons. For non-parametric data, Kruskall-Wallis test with Dunn's post-test and Benjamini- Hochberg correction for multiple comparisons were used. Microarray data was analyzed with linear modelling (limma) with Benjamini Hochberg correction for multiple comparisons. Incapacitance data were analyzed with a mixed effect linear model with pairwise comparisons at the different time points (Tukey correction of $P$ values for multiple comparisons). The proportion of nuclear/cytoplasmic YAP staining was compared using a generalized linear model. Tests were two-sided and $P$ values $<0.05$ were considered significant. Individual tests used and specific $P$ values are indicated in figure legends. 


\section{List of supplementary materials}

Materials and methods

Fig. S1. Relationship between ROR2, WNT5A, YAP, CTGF and SOX9 in in human osteoarthritic cartilage and healthy normal cartilage.

Fig. S2. ROR2 Immunostaining in murine femoral head cartilage.

Fig. S3. ROR2/WNT5A expression correlates with chondrocytic differentiation.

Fig. S4. ROR2 overexpression, and silencing efficiency of ROR2 siRNA and shRNA.

Fig. S5. Silencing efficiency of atelocollagen-conjugated ROR2 siRNA in vivo

Fig. S6. Treatment with ROR2i in the MLI model of osteoarthritis in mice.

Fig. S7. Four weeks of treatment with ROR2i in the MLI model of osteoarthritis in mice.

Fig. S8. ROR2 mRNA expression in HEK293 and C3H10T1² cell lines.

Fig. S9. WNT5A/ROR2 signaling induces nuclear accumulation of YAP in a G-protein and Rho dependent manner.

Fig. S10. ROR2 blockade supports cartilage homeostasis by suppressing YAP signaling.

Fig. S11. Mouse skin scoring system.

Fig. S12. Histomorphometrical analysis of joint tissues.

Fig. S13. Toluidine Blue quantification.

Table S1. Mouse serum analysis following 10 weeks of treatment with control siRNA or ROR2i.

Table S2. Mouse skin scoring system.

Table S3. Real-time PCR primer sequences. 


\section{References}

1. T. Neogi, The epidemiology and impact of pain in osteoarthritis, Osteoarthritis and Cartilage 21, 1145-1153 (2013).

2. M. Hiligsmann, C. Cooper, N. Arden, M. Boers, J. C. Branco, M. Luisa Brandi, O. Bruyère, F. Guillemin, M. C. Hochberg, D. J. Hunter, J. A. Kanis, T. K. Kvien, A. Laslop, J.-P. Pelletier, D. Pinto, S. Reiter-Niesert, R. Rizzoli, L. C. Rovati, J. L. H. Severens, S. Silverman, Y. Tsouderos, P. Tugwell, J.-Y. Reginster, Health economics in the field of osteoarthritis: an expert's consensus paper from the European Society for Clinical and Economic Aspects of Osteoporosis and Osteoarthritis (ESCEO), Semin. Arthritis Rheum. 43, 303-313 (2013).

3. J. Hubertsson, I. F. Petersson, C. A. Thorstensson, M. Englund, Risk of sick leave and disability pension in working-age women and men with knee osteoarthritis, Ann Rheum Dis 72, 401-405 (2013).

4. H. Kotlarz, C. L. Gunnarsson, H. Fang, J. A. Rizzo, Insurer and out-of-pocket costs of osteoarthritis in the US: evidence from national survey data, Arthritis Rheum. 60, 3546-3553 (2009).

5. A. Turkiewicz, I. F. Petersson, J. Björk, G. Hawker, L. E. Dahlberg, L. S. Lohmander, M. Englund, Current and future impact of osteoarthritis on health care: a population-based study with projections to year 2032, Osteoarthritis and Cartilage 22, 1826-1832 (2014).

6. N. Verzijl, J. DeGroot, S. R. Thorpe, R. A. Bank, J. N. Shaw, T. J. Lyons, J. W. J. Bijlsma, F. P. J. G. Lafeber, J. W. Baynes, J. M. TeKoppele, Effect of Collagen Turnover on the Accumulation of Advanced Glycation End Products, J. Biol. Chem. 275, 39027-39031 (2000).

7. J. A. Buckwalter, C. Saltzman, T. Brown, The Impact of Osteoarthritis, , 6-15 (2004).

8. J. C. Sherwood, J. Bertrand, S. E. Eldridge, F. Dell'Accio, Cellular and molecular mechanisms of cartilage damage and repair, Drug discovery today 19, 1172-1177 (2014).

9. S. S. Glasson, R. Askew, B. Sheppard, B. Carito, T. Blanchet, H.-L. Ma, C. R. Flannery, D. Peluso, K. Kanki, Z. Yang, M. K. Majumdar, E. A. Morris, Deletion of active ADAMTS5 prevents cartilage degradation in a murine model of osteoarthritis, Nature 434, 644-648 (2005).

10. H. Nagase, M. Kashiwagi, Aggrecanases and cartilage matrix degradation, Arthritis Res. Ther. 5, 94-103 (2003).

11. H. Stanton, F. M. Rogerson, C. J. East, S. B. Golub, K. E. Lawlor, C. T. Meeker, C. B. Little, K. Last, P. J. Farmer, I. K. Campbell, A. M. Fourie, A. J. Fosang, ADAMTS5 is the major aggrecanase in mouse cartilage in vivo and in vitro, Nature 434, 648-652 (2005).

12. M. C. Castaño Betancourt, F. Cailotto, H. J. Kerkhof, F. M. F. Cornelis, S. A. Doherty, D. J. Hart, A. Hofman, F. P. Luyten, R. A. Maciewicz, M. Mangino, S. Metrustry, K. Muir, M. J. Peters, F. Rivadeneira, M. Wheeler, W. Zhang, N. Arden, T. D. Spector, A. G. Uitterlinden, M. 
Doherty, R. J. U. Lories, A. M. Valdes, J. B. J. van Meurs, Genome-wide association and functional studies identify the DOT1L gene to be involved in cartilage thickness and hip osteoarthritis, Proc. Natl. Acad. Sci. U.S.A. 109, 8218-8223 (2012).

13. J. M. Kerkhof, A. G. Uitterlinden, A. M. Valdes, D. J. Hart, F. Rivadeneira, M. Jhamai, A. Hofman, H. a. P. Pols, S. M. A. Bierma-Zeinstra, T. D. Spector, J. B. van Meurs, Radiographic osteoarthritis at three joint sites and FRZB, LRP5, and LRP6 polymorphisms in two populationbased cohorts, Osteoarthr. Cartil. 16, 1141-1149 (2008).

14. R. J. Lories, S. Boonen, J. Peeters, K. de Vlam, F. P. Luyten, Evidence for a differential association of the Arg200Trp single-nucleotide polymorphism in FRZB with hip osteoarthritis and osteoporosis, Rheumatology (Oxford) 45, 113-114 (2006).

15. R. J. U. Lories, J. Peeters, K. Szlufcik, P. Hespel, F. P. Luyten, Deletion of frizzled-related protein reduces voluntary running exercise performance in mice, Osteoarthr. Cartil. 17, 390-396 (2009).

16. R. J. U. Lories, J. Peeters, A. Bakker, P. Tylzanowski, I. Derese, J. Schrooten, J. T. Thomas, F. P. Luyten, Articular cartilage and biomechanical properties of the long bones in Frzbknockout mice, Arthritis Rheum. 56, 4095-4103 (2007).

17. J. Loughlin, B. Dowling, K. Chapman, L. Marcelline, Z. Mustafa, L. Southam, A. Ferreira, C. Ciesielski, D. A. Carson, M. Corr, Functional variants within the secreted frizzled-related protein 3 gene are associated with hip osteoarthritis in females, Proc. Natl. Acad. Sci. U.S.A. 101, 9757-9762 (2004).

18. B. Gao, H. Song, K. Bishop, G. Elliot, L. Garrett, M. English, P. Andre, J. Robinson, R. Sood, Y. Minami, A. N. Economides, Y. Yang, Wnt signaling gradients establish planar cell polarity by inducing Vangl2 phosphorylation through Ror2, Dev Cell 20, 163-176 (2011).

19. S. Yamamoto, O. Nishimura, K. Misaki, M. Nishita, Y. Minami, S. Yonemura, H. Tarui, H. Sasaki, Cthrc1 selectively activates the planar cell polarity pathway of Wnt signaling by stabilizing the Wnt-receptor complex, Dev. Cell 15, 23-36 (2008).

20. J.-S. Mo, H. W. Park, K.-L. Guan, The Hippo signaling pathway in stem cell biology and cancer, EMBO Rep. 15, 642-656 (2014).

21. H. W. Park, Y. C. Kim, B. Yu, T. Moroishi, J.-S. Mo, S. W. Plouffe, Z. Meng, K. C. Lin, F.X. Yu, C. M. Alexander, C.-Y. Wang, K.-L. Guan, Alternative Wnt Signaling Activates YAP/TAZ, Cell 162, 780-794 (2015).

22. M. Enomoto-Iwamoto, J. Kitagaki, E. Koyama, Y. Tamamura, C. Wu, N. Kanatani, T. Koike, H. Okada, T. Komori, T. Yoneda, V. Church, P. H. Francis-West, K. Kurisu, T. Nohno, M. Pacifici, M. Iwamoto, The Wnt Antagonist Frzb-1 Regulates Chondrocyte Maturation and Long Bone Development during Limb Skeletogenesis, Developmental Biology 251, 142-156 (2002). 
23. T. Saito, A. Fukai, A. Mabuchi, T. Ikeda, F. Yano, S. Ohba, N. Nishida, T. Akune, N. Yoshimura, T. Nakagawa, K. Nakamura, K. Tokunaga, U. Chung, H. Kawaguchi, Transcriptional regulation of endochondral ossification by HIF-2 $\alpha$ during skeletal growth and osteoarthritis development, Nat Med 16, 678-686 (2010).

24. S. Yang, J. Kim, J.-H. Ryu, H. Oh, C.-H. Chun, B. J. Kim, B. H. Min, J.-S. Chun, Hypoxiainducible factor-2alpha is a catabolic regulator of osteoarthritic cartilage destruction, Nat. Med. 16, 687-693 (2010).

25. R. Al-Shawi, S. V. Ashton, C. Underwood, J. P. Simons, Expression of the Ror1 and Ror2 receptor tyrosine kinase genes during mouse development, Dev. Genes Evol. 211, 161-171 (2001).

26. T. M. DeChiara, R. B. Kimble, W. T. Poueymirou, J. Rojas, P. Masiakowski, D. M. Valenzuela, G. D. Yancopoulos, Ror2, encoding a receptor-like tyrosine kinase, is required for cartilage and growth plate development, Nat Genet 24, 271-274 (2000).

27. A. R. Afzal, A. Rajab, C. D. Fenske, M. Oldridge, N. Elanko, E. Ternes-Pereira, B. Tüysüz, V. A. Murday, M. A. Patton, A. O. Wilkie, S. Jeffery, Recessive Robinow syndrome, allelic to dominant brachydactyly type B, is caused by mutation of ROR2, Nat. Genet. 25, 419-422 (2000).

28. G. C. Schwabe, B. Trepczik, K. Süring, N. Brieske, A. S. Tucker, P. T. Sharpe, Y. Minami, S. Mundlos, Ror2 knockout mouse as a model for the developmental pathology of autosomal recessive Robinow syndrome, Dev. Dyn. 229, 400-410 (2004).

29. K. Ijiri, L. F. Zerbini, H. Peng, H. H. Otu, K. Tsuchimochi, M. Otero, C. Dragomir, N. Walsh, B. E. Bierbaum, D. Mattingly, G. van Flandern, S. Komiya, T. Aigner, T. A. Libermann, M. B. Goldring, Differential expression of GADD45beta in normal and osteoarthritic cartilage: potential role in homeostasis of articular chondrocytes, Arthritis Rheum. 58, 2075-2087 (2008).

30. F. He, W. Xiong, X. Yu, R. Espinoza-Lewis, C. Liu, S. Gu, M. Nishita, K. Suzuki, G. Yamada, Y. Minami, Y. Chen, Wnt5a regulates directional cell migration and cell proliferation via Ror2-mediated noncanonical pathway in mammalian palate development, Development 135, 3871-3879 (2008).

31. I. Oishi, H. Suzuki, N. Onishi, R. Takada, S. Kani, B. Ohkawara, I. Koshida, K. Suzuki, G. Yamada, G. C. Schwabe, S. Mundlos, H. Shibuya, S. Takada, Y. Minami, The receptor tyrosine kinase Ror2 is involved in non-canonical Wnt5a/JNK signalling pathway, Genes to Cells 8, 645654 (2003).

32. A. Schambony, D. Wedlich, Wnt-5A/Ror2 regulate expression of XPAPC through an alternative noncanonical signaling pathway, Dev. Cell 12, 779-792 (2007).

33. V. Wallkamm, R. Dörlich, K. Rahm, T. Klessing, G. U. Nienhaus, D. Wedlich, D. Gradl, Live imaging of Xwnt5A-ROR2 complexes, PLOS ONE 9, e109428 (2014). 
34. R. F. Loeser, A. L. Olex, M. A. McNulty, C. S. Carlson, M. Callahan, C. Ferguson, J. S. Fetrow, Disease progression and phasic changes in gene expression in a mouse model of osteoarthritis, PLoS ONE 8, e54633 (2013).

35. F. Comblain, J.-E. Dubuc, C. Lambert, C. Sanchez, I. Lesponne, S. Serisier, Y. Henrotin, Identification of Targets of a New Nutritional Mixture for Osteoarthritis Management Composed by Curcuminoids Extract, Hydrolyzed Collagen and Green Tea Extract, PLoS ONE 11, e0156902 (2016).

36. F. Dell'Accio, C. De Bari, F. P. Luyten, Molecular markers predictive of the capacity of expanded human articular chondrocytes to form stable cartilage in vivo, Arthritis Rheum. 44, 1608-1619 (2001).

37. B. Ma, J. C. H. Leijten, L. Wu, M. Kip, C. A. van Blitterswijk, J. N. Post, M. Karperien, Gene expression profiling of dedifferentiated human articular chondrocytes in monolayer culture, Osteoarthritis and Cartilage 21, 599-603 (2013).

38. C. De Bari, F. Dell'Accio, P. Tylzanowski, F. P. Luyten, Multipotent mesenchymal stem cells from adult human synovial membrane, Arthritis \& Rheumatism 44, 1928-1942 (2001).

39. A. E. Denker, A. R. Haas, S. B. Nicoll, R. S. Tuan, Chondrogenic differentiation of murine C3H10T1/2 multipotential mesenchymal cells: I. Stimulation by bone morphogenetic protein-2 in high-density micromass cultures, Differentiation 64, 67-76 (1999).

40. S. Byun, Y. L. Sinskey, Y. C. S. Lu, T. Ort, K. Kavalkovich, P. Sivakumar, E. B. Hunziker, E. H. Frank, A. J. Grodzinsky, Transport of anti-IL-6 antigen binding fragments into cartilage and the effects of injury, Arch Biochem Biophys 532, 15-22 (2013).

41. A. Maroudas, Transport of solutes through cartilage: permeability to large molecules, $J$. Anat. 122, 335-347 (1976).

42. D. Diarra, M. Stolina, K. Polzer, J. Zwerina, M. S. Ominsky, D. Dwyer, A. Korb, J. Smolen, M. Hoffmann, C. Scheinecker, D. van der Heide, R. Landewe, D. Lacey, W. G. Richards, G. Schett, Dickkopf-1 is a master regulator of joint remodeling, Nat. Med. 13, 156-163 (2007).

43. A. Distler, C. Ziemer, C. Beyer, N.-Y. Lin, C.-W. Chen, K. Palumbo-Zerr, C. Dees, A. Weidemann, O. Distler, G. Schett, J. H. W. Distler, Inactivation of evenness interrupted (EVI) reduces experimental fibrosis by combined inhibition of canonical and non-canonical Wnt signalling, Ann. Rheum. Dis. 73, 624-627 (2014).

44. D. Hamada, E. R. Sampson, R. D. Maynard, M. J. Zuscik, Surgical induction of posttraumatic osteoarthritis in the mouse, Methods Mol. Biol. 1130, 61-72 (2014).

45. K. Johnson, S. Zhu, M. S. Tremblay, J. N. Payette, J. Wang, L. C. Bouchez, S. Meeusen, A. Althage, C. Y. Cho, X. Wu, P. G. Schultz, A stem cell-based approach to cartilage repair, Science 336, 717-721 (2012). 
46. E. R. Sampson, M. J. Hilton, Y. Tian, D. Chen, E. M. Schwarz, R. A. Mooney, S. V. Bukata, R. J. O’Keefe, H. Awad, J. E. Puzas, R. N. Rosier, M. J. Zuscik, Teriparatide as a chondroregenerative therapy for injury-induced osteoarthritis, Sci Transl Med 3, 101ra93 (2011).

47. S. Kamekura, K. Hoshi, T. Shimoaka, U. Chung, H. Chikuda, T. Yamada, M. Uchida, N. Ogata, A. Seichi, K. Nakamura, H. Kawaguchi, Osteoarthritis development in novel experimental mouse models induced by knee joint instability, Osteoarthritis and Cartilage 13, 632-641 (2005).

48. F. Dell'Accio, C. De Bari, F. P. Luyten, Microenvironment and phenotypic stability specify tissue formation by human articular cartilage-derived cells in vivo, Experimental cell research 287, 16-27 (2003).

49. S. Eldridge, G. Nalesso, H. Ismail, K. Vicente-Greco, P. Kabouridis, M. Ramachandran, A. Niemeier, J. Herz, C. Pitzalis, M. Perretti, F. Dell'Accio, Agrin mediates chondrocyte homeostasis and requires both LRP4 and $\alpha$-dystroglycan to enhance cartilage formation in vitro and in vivo, Ann. Rheum. Dis. 75, 1228-1235 (2016).

50. G. Nalesso, J. Sherwood, J. Bertrand, T. Pap, M. Ramachandran, C. De Bari, C. Pitzalis, F. Dell'accio, WNT-3A modulates articular chondrocyte phenotype by activating both canonical and noncanonical pathways, J. Cell Biol. 193, 551-564 (2011).

51. A. Mikels, Y. Minami, R. Nusse, Ror2 receptor requires tyrosine kinase activity to mediate Wnt5A signaling, J. Biol. Chem. 284, 30167-30176 (2009).

52. A. J. Mikels, R. Nusse, Purified Wnt5a protein activates or inhibits beta-catenin-TCF signaling depending on receptor context, PLoS Biol. 4, e115 (2006).

53. L. Grumolato, G. Liu, P. Mong, R. Mudbhary, R. Biswas, R. Arroyave, S. Vijayakumar, A. N. Economides, S. A. Aaronson, Canonical and noncanonical Wnts use a common mechanism to activate completely unrelated coreceptors, Genes Dev. 24, 2517-2530 (2010).

54. C. Hartmann, C. J. Tabin, Dual roles of Wnt signaling during chondrogenesis in the chicken limb, Development 127, 3141-3159 (2000).

55. J. A. Rudnicki, A. M. Brown, Inhibition of chondrogenesis by Wnt gene expression in vivo and in vitro, Dev. Biol. 185, 104-118 (1997).

56. J. Yu, L. Chen, B. Cui, G. F. Widhopf, Z. Shen, R. Wu, L. Zhang, S. Zhang, S. P. Briggs, T. J. Kipps, Wnt5a induces ROR1/ROR2 heterooligomerization to enhance leukemia chemotaxis and proliferation, J Clin Invest 126, 585-598.

57. E. N. Blaney Davidson, E. L. Vitters, M. B. Bennink, P. L. E. M. van Lent, a P. M. van Caam, A. B. Blom, W. B. van den Berg, F. A. J. van de Loo, P. M. van der Kraan, E. N. B. Davidson, P. L. E. M. V. Lent, A. P. M. V. Caam, W. B. V. D. Berg, F. A. J. V. D. Loo, P. M. V. D. Kraan, F. A. J. van de Loo, W. B. van den Berg, P. M. van der Kraan, Inducible chondrocytespecific overexpression of BMP2 in young mice results in severe aggravation of osteophyte 
formation in experimental OA without altering cartilage damage., Annals of the rheumatic diseases 16, 210 (2014).

58. E. N. Blaney Davidson, E. L. Vitters, P. M. van der Kraan, W. B. van den Berg, Expression of transforming growth factor-beta (TGFbeta) and the TGFbeta signalling molecule SMAD-2P in spontaneous and instability-induced osteoarthritis: role in cartilage degradation, chondrogenesis and osteophyte formation., Annals of the rheumatic diseases 65, 1414-21 (2006).

59. P. M. van der Kraan, E. N. Blaney Davidson, W. B. van den Berg, Bone morphogenetic proteins and articular cartilage: To serve and protect or a wolf in sheep clothing's?, Osteoarthr. Cartil. 18, 735-741 (2010).

60. R. K. Hoyles, K. Khan, X. Shiwen, S. L. Howat, G. E. Lindahl, P. Leoni, R. M. du Bois, A. U. Wells, C. M. Black, D. J. Abraham, C. P. Denton, Fibroblast-specific perturbation of transforming growth factor beta signaling provides insight into potential pathogenic mechanisms of scleroderma-associated lung fibrosis: exaggerated response to alveolar epithelial injury in a novel mouse model, Arthritis Rheum. 58, 1175-1188 (2008).

61. B. Caramés, A. Hasegawa, N. Taniguchi, S. Miyaki, F. J. Blanco, M. Lotz, Autophagy activation by rapamycin reduces severity of experimental osteoarthritis, Ann. Rheum. Dis. 71, 575-581 (2012).

62. K. Fitzgerald, S. White, A. Borodovsky, B. R. Bettencourt, A. Strahs, V. Clausen, P. Wijngaard, J. D. Horton, J. Taubel, A. Brooks, C. Fernando, R. S. Kauffman, D. Kallend, A. Vaishnaw, A. Simon, A Highly Durable RNAi Therapeutic Inhibitor of PCSK9, N. Engl. J. Med. 376, 41-51 (2017).

63. G. Monteleone, M. F. Neurath, S. Ardizzone, A. Di Sabatino, M. C. Fantini, F. Castiglione, M. L. Scribano, A. Armuzzi, F. Caprioli, G. C. Sturniolo, F. Rogai, M. Vecchi, R. Atreya, F. Bossa, S. Onali, M. Fichera, G. R. Corazza, L. Biancone, V. Savarino, R. Pica, A. Orlando, F. Pallone, Mongersen, an oral SMAD7 antisense oligonucleotide, and Crohn's disease, N. Engl. J. Med. 372, 1104-1113 (2015).

64. K. J. Pasi, S. Rangarajan, P. Georgiev, T. Mant, M. D. Creagh, T. Lissitchkov, D. Bevan, S. Austin, C. R. Hay, I. Hegemann, R. Kazmi, P. Chowdary, L. Gercheva-Kyuchukova, V. Mamonov, M. Timofeeva, C.-H. Soh, P. Garg, A. Vaishnaw, A. Akinc, B. Sørensen, M. V. Ragni, Targeting of Antithrombin in Hemophilia A or B with RNAi Therapy, New England Journal of Medicine 377, 819-828 (2017).

65. C. D. DiDomenico, Z. Xiang Wang, L. J. Bonassar, Cyclic Mechanical Loading Enhances Transport of Antibodies Into Articular Cartilage, J Biomech Eng 139 (2017), doi:10.1115/1.4035265.

66. M. B. Goldring, J. R. Birkhead, L. F. Suen, R. Yamin, S. Mizuno, J. Glowacki, J. L. Arbiser, J. F. Apperley, Interleukin-1 beta-modulated gene expression in immortalized human chondrocytes, J. Clin. Invest. 94, 2307-2316 (1994). 
67. F. E. Grubbs, Procedures for Detecting Outlying Observations in Samples, Technometrics 11, 1-21 (1969).

68. F. E. Grubbs, Sample Criteria for Testing Outlying Observations, Ann. Math. Statist. 21, 2758 (1950).

69. H. J. Mankin, H. Dorfman, L. Lippiello, A. Zarins, Biochemical and metabolic abnormalities in articular cartilage from osteo-arthritic human hips. II. Correlation of morphology with biochemical and metabolic data, J Bone Joint Surg Am 53, 523-537 (1971).

70. C. De Bari, F. Dell'Accio, F. P. Luyten, Human periosteum-derived cells maintain phenotypic stability and chondrogenic potential throughout expansion regardless of donor age, Arthritis \& Rheumatism 44, 85-95 (2001).

71. C. A. Schneider, W. S. Rasband, K. W. Eliceiri, NIH Image to ImageJ: 25 years of image analysis, Nat Meth 9, 671-675 (2012).

72. K.-W. Chong, A. Chanalaris, A. Burleigh, H. Jin, F. E. Watt, J. Saklatvala, T. L. Vincent, Fibroblast growth factor 2 drives changes in gene expression following injury to murine cartilage in vitro and in vivo, Arthritis Rheum. 65, 2346-2355 (2013).

73. J. Gruber, T. L. Vincent, M. Hermansson, M. Bolton, R. Wait, J. Saklatvala, Induction of interleukin-1 in articular cartilage by explantation and cutting, Arthritis Rheum. 50, 2539-2546 (2004).

74. B. Zhao, X. Wei, W. Li, R. S. Udan, Q. Yang, J. Kim, J. Xie, T. Ikenoue, J. Yu, L. Li, P. Zheng, K. Ye, A. Chinnaiyan, G. Halder, Z.-C. Lai, K.-L. Guan, Inactivation of YAP oncoprotein by the Hippo pathway is involved in cell contact inhibition and tissue growth control, Genes Dev. 21, 2747-2761 (2007).

75. J. Sherwood, J. Bertrand, G. Nalesso, B. Poulet, A. Pitsillides, L. Brandolini, A. Karystinou, C. De Bari, F. P. Luyten, C. Pitzalis, T. Pap, F. Dell'Accio, A homeostatic function of CXCR2 signalling in articular cartilage, Ann. Rheum. Dis. 74, 2207-2215 (2015).

76. R. Corder, Evaluation of endothelin-converting enzyme inhibitors using cultured cells, Methods Mol. Biol. 206, 147-164 (2002).

77. S. S. Glasson, T. J. Blanchet, E. A. Morris, The surgical destabilization of the medial meniscus (DMM) model of osteoarthritis in the 129/SvEv mouse, Osteoarthr. Cartil. 15, 10611069 (2007).

78. B. Poulet, R. de Souza, A. V. Kent, L. Saxon, O. Barker, A. Wilson, Y.-M. Chang, M. Cake, A. A. Pitsillides, Intermittent applied mechanical loading induces subchondral bone thickening that may be intensified locally by contiguous articular cartilage lesions, Osteoarthr. Cartil. 23, 940-948 (2015).

79. G. Nalesso, B. L. Thomas, J. C. Sherwood, J. Yu, O. Addimanda, S. E. Eldridge, A.-S. Thorup, L. Dale, G. Schett, J. Zwerina, N. Eltawil, C. Pitzalis, F. Dell’Accio, WNT16 
antagonises excessive canonical WNT activation and protects cartilage in osteoarthritis, Ann. Rheum. Dis. 76, 218-226 (2017).

80. S. S. Glasson, M. G. Chambers, W. B. Van Den Berg, C. B. Little, The OARSI

histopathology initiative - recommendations for histological assessments of osteoarthritis in the mouse, Osteoarthr. Cartil. 18 Suppl 3, S17-23 (2010). 


\section{Funding}

We gratefully acknowledge funding support of this work by the Medical College of St

Bartholomew's Hospital Trust, the William Harvey Research Foundation, FOREUM foundation for research in rheumatology (1016807), the MRC (MR/L022893/1, MR/N010973/1, MR/P026362/1, MR/K013076/1), Versus Arthritis (21515, 20886, 21621, 20859), and the DFG Emmy-Noether program (BE4328/5-1).

\section{Author contributions}

Inception of the study: F.D. and A.-S.T. Experimental design: F.D., A.-S.T., J.B. Execution of the experiments: A.-S.T., F.D., B.P., D.S., S.C., B.L.T., G.N., T.A., C.P., R.C., J.R.W. Interpretation of results: A.-S.T., F.D., B.L.T., S.E.E. Writing of the manuscript: A.-S.T., F.D.

\section{Competing interests}

The authors have not conducted any paid or unpaid consultation regarding this work. F.D. has consulted for Samumed and UCB (not relevant to this study). F.D. and A.-S.T. are co-inventors on a patent application submitted by QMUL that covers the subject of this work (WO2019/097247 A1: ROR2 inhibitors and use thereof in treating and/or preventing cartilage loss).

\section{Data and materials availability}

All data associated with this study are present in the paper or the Supplementary Materials. All plasmids are publicly available from Addgene. Microarray data were mined from GEO accession GSE41342, GSE75181. 


\section{Figure Legends}

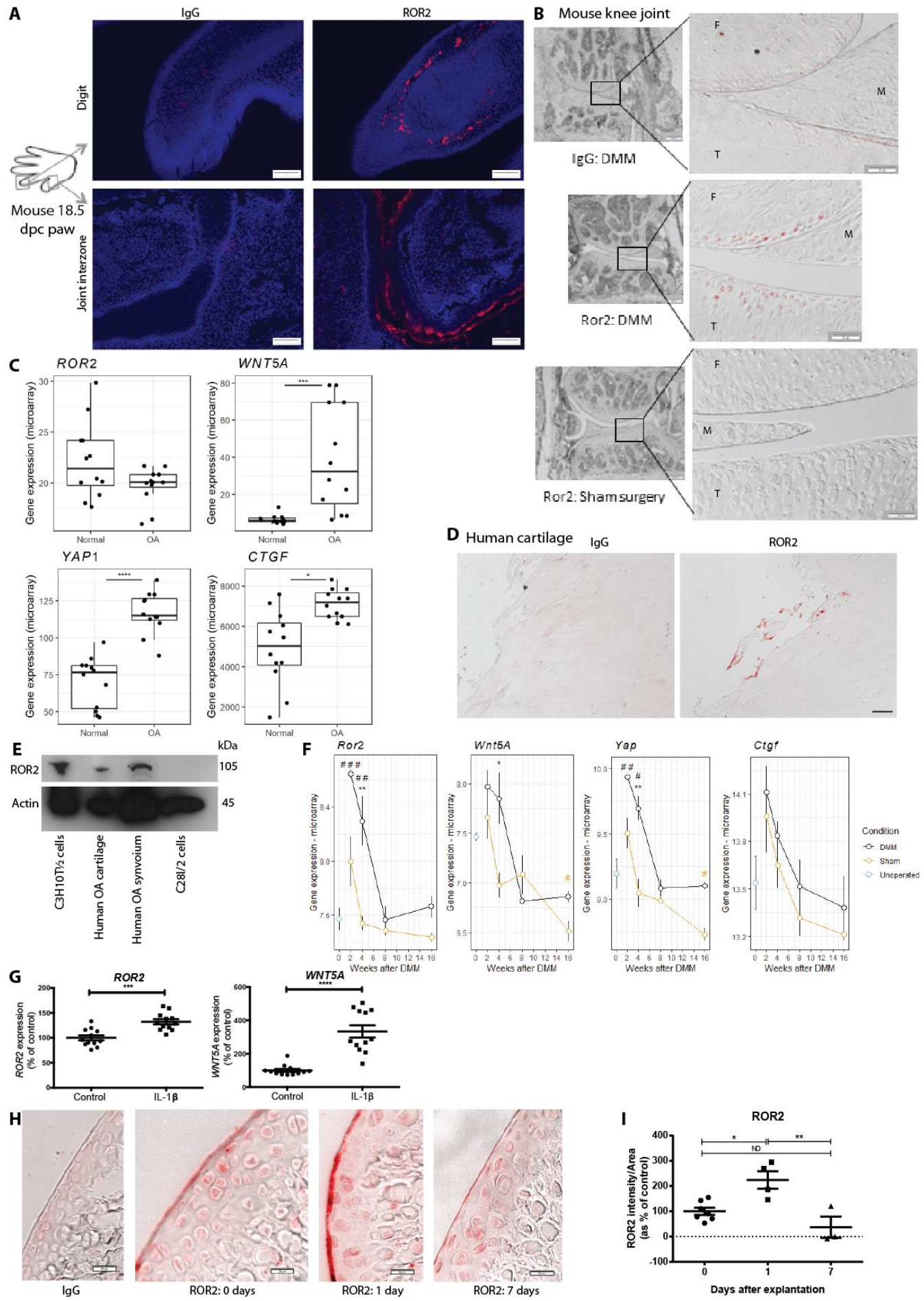

Fig. 1. ROR2 expression is upregulated in osteoarthritis 
(A) ROR2 expression (red) in the periarticular perichondrium and joint interzone of a murine paw at 18.5 days post coitum (dpc). Dapi (blue), bars, $100 \mu \mathrm{m}$. (B) Immunostaining of ROR2 (red) in murine articular cartilage one week after destabilization of the medial meniscus (DMM) compared to sham-operated control joint. Bars, $50 \mu \mathrm{m}$; F, femur; M, meniscus; T, tibia. Insets shown at higher magnification on right. (C) ROR2, WNT5A, YAP and CTGF expression in human osteoarthritic cartilage (OA) versus healthy normal cartilage, $n=12$, linear modeling (limma) with Benjamini-Hochberg correction for multiple comparison. WNT5A $\mathrm{P}=0.00028$, $C T G F \mathrm{P}=0.028, Y A P \mathrm{P}=0.000036$. Box and whiskers plots show all values, line at the median, boxes extend from the 25th to 75th percentiles, error bars span max to min values (29). (D) ROR2 expression (red) in full-thickness human articular cartilage from a patient undergoing total knee replacement for osteoarthritis. Bars, $200 \mu \mathrm{m}$. (E) Western blot for ROR2 in articular cartilage and synovium from a patient undergoing total knee replacement for osteoarthritis, $\mathrm{n}=1$. Whole cell lysate of $\mathrm{C} 3 \mathrm{H} 10 \mathrm{~T}^{1} / 2$ cells and C28/I2 cells were used as positive and negative controls, respectively. (F) Temporal regulation of Ror2, Wnt5A, Yap and Ctgf in the murine joint after DMM, GEO accession GSE41342, n= 9 mice at each timepoint. Circles show mean, error bars are standard error of the mean, two-way ANOVA with Tukey's HSD post-hoc test (\# in black refers to differences between DMM vs unoperated controls, or in yellow between shamoperated vs unoperated controls, * between DMM vs sham), Ror2 \#\# P = 0.00039, \#\# P = $0.0079, * * \mathrm{P}=0.0054 ;$ Wnt5A \# $\mathrm{P}=0.016,{ }^{*} \mathrm{P}=0.032 ;$ Yap \#\# $\mathrm{P}=0.0011, \# \mathrm{P}=0.017,16$ week sham \# $\mathrm{P}=0.031, * * \mathrm{P}=0.0014 .(\mathbf{G})$ ROR2 and WNT5A expression in human articular chondrocytes stimulated with $10 \mu \mathrm{M} \mathrm{IL}-1 \beta$ for 24 hrs. GEO accession GSE75181, n=12 patients, line at mean, error bars show standard error of the mean, class comparison test based on a paired t-test with Benjamini-Hochberg correction, $* * * \mathrm{P}=0.00079$, $* * * * \mathrm{P}=0.00000026$. (H) ROR2 
expression (red) in murine femoral hip caps explanted from subchondral bone and cultured ex vivo for indicated times. Bars, $25 \mu \mathrm{m}$. (I) Quantification of the ROR2 staining in the articular cartilage, from images in fig. S2B. $n=7$ (0 days), 4 (1 day) and 3 (7 days) hip caps, line at mean, error bars show standard error of the mean, ANOVA with Tukey's HSD post-hoc test, * $\mathrm{P}=$ $0.011 ; * * \mathrm{P}=0.0026$ 
A

\section{Extracted Alcian Blue}

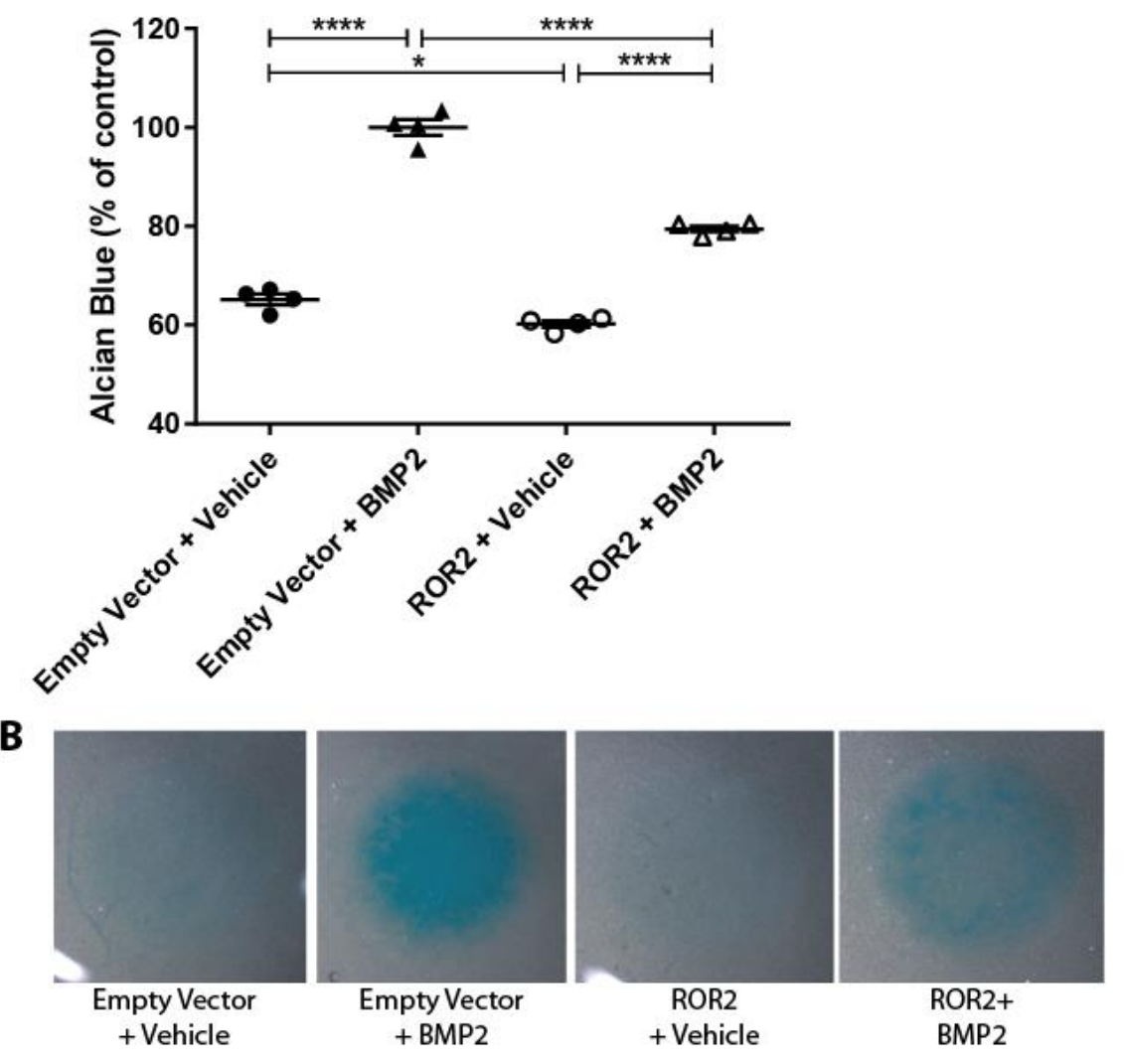

C

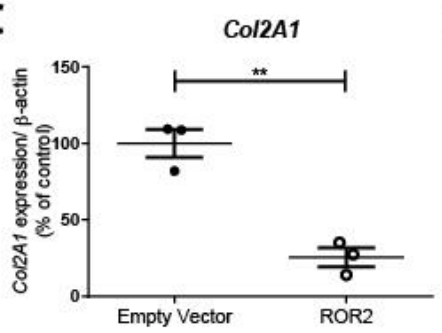

D

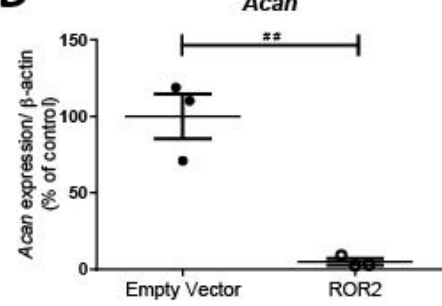

$\mathbf{F}$

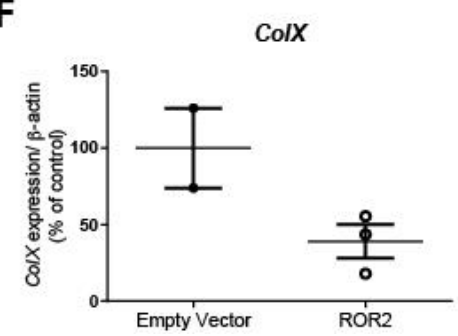

G

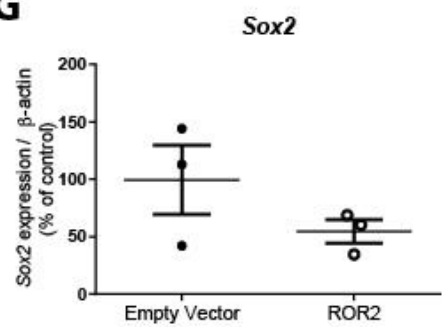

E

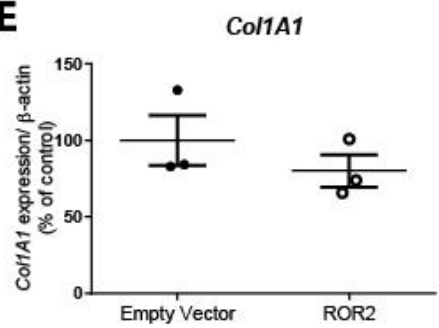

H

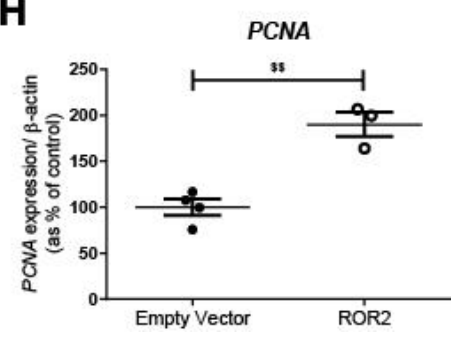

Fig. 2. ROR2 overexpression inhibits chondrogenesis

(A) Glycosaminoglycan content in $\mathrm{C} 3 \mathrm{H} 10 \mathrm{~T}^{1} / 2$ cells transfected with ROR2 or empty vector, cultured in micromass for 3 days $\pm 100 \mathrm{ng} / \mathrm{ml} \mathrm{BMP} 2$ and stained with Alcian blue. Extracted 
Alcian blue was quantified. $\mathrm{n}=4$, line at mean, error bars show standard error of the mean, twoway ANOVA with Tukey's HSD post-hoc test, $* \mathrm{P}=0.033$, all other comparisons $* * * * \mathrm{P}$ $<0.0001$. (B) Representative images of Alcian blue staining from (A). (C-H) Chondrogenic differentiation markers in $\mathrm{C} 3 \mathrm{H} 10 \mathrm{~T}^{1} / 2$ cells transfected with ROR2 or empty vector and cultured in micromass for 3 days, gene expression compared by real-time PCR analysis. $n=2-4$, line at mean, error bars show standard error of the mean, unpaired t-test, $* * P=0.0024$, \#\# $\mathrm{P}=0.0031$, $\$ \$ \mathrm{P}=0.0019$. Col2al, collagen type II; Acan, Aggrecan; Collal, collagen type I; ColX, collagen type 10 . 

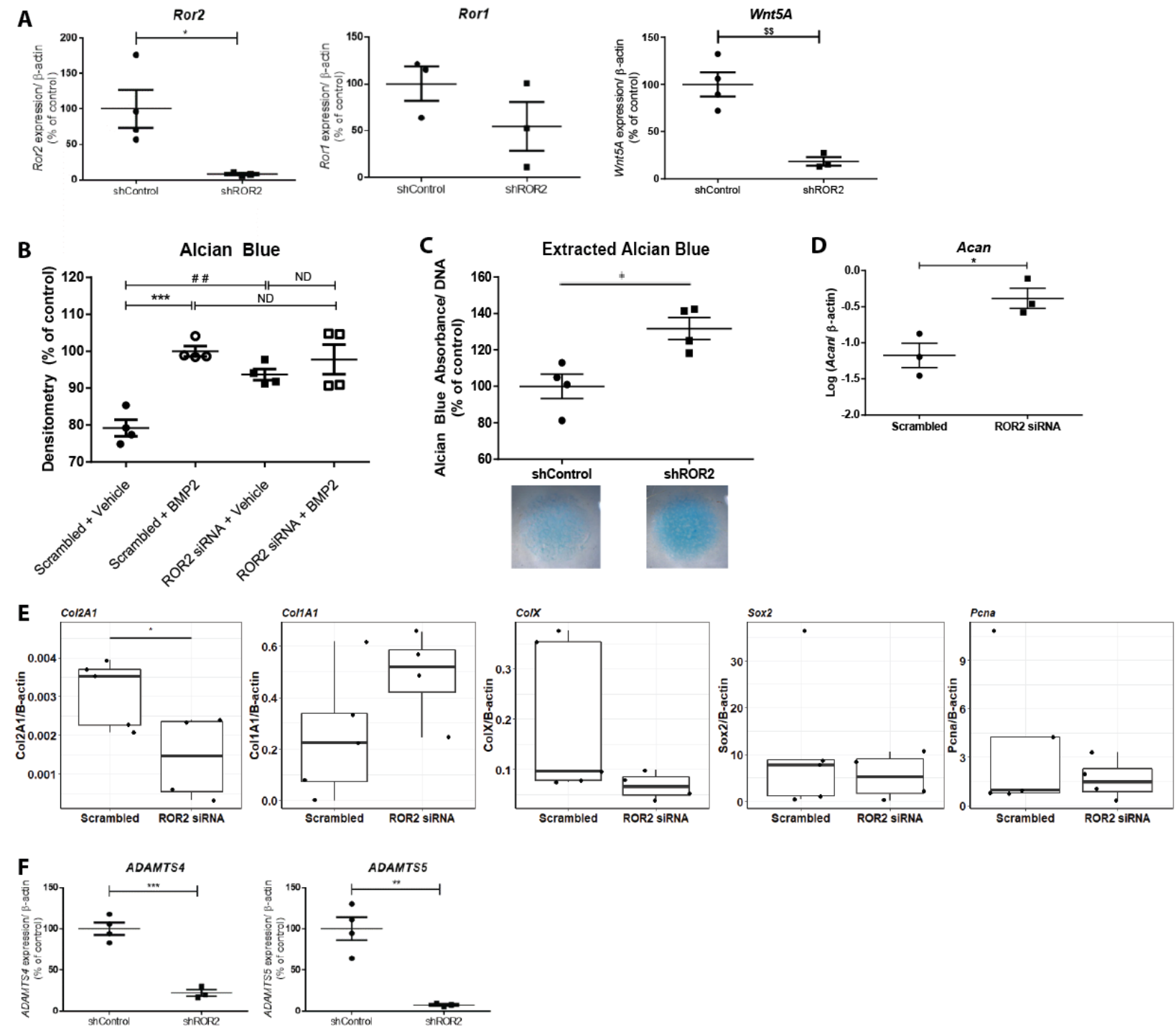

Fig. 3. Silencing ROR2 induces chondrogenesis

(A) Real-time PCR analysis showing Ror2-silencing efficiency of lentiviral ROR2 shRNA in C3H10T $1 \frac{1}{2}$ cells. $\mathrm{n}=3-4$, unpaired t-test, $* \mathrm{P}=0.033, \$ \$ \mathrm{P}=0.0034$. (B) Glycosaminoglycan content in $\mathrm{C}_{3} \mathrm{H}_{10} \mathrm{~T}^{1} / 2$ cells transfected with ROR2- or scrambled siRNA cultured in micromass for 3 days $\pm 100 \mathrm{ng} / \mathrm{ml}$ BMP2. Micromasses were stained with Alcian blue and compared by densitometry, $\mathrm{n}=4$, two-way ANOVA with Tukey's HSD post-hoc test, ${ }^{* * *} \mathrm{P}=0.00040,{ }^{\# \#} \mathrm{P}=$ 0.0072. (C) $\mathrm{C} 3 \mathrm{H} 10 \mathrm{~T}^{1} / 2$ cells expressing ROR2- or control shRNA were cultured in micromass 
for 3 days and stained with Alcian blue. Extracted Alcian blue was quantified and normalized for DNA content, $\mathrm{n}=4$. Representative images shown below. Unpaired t-test, $\mathrm{P}=0.013$. (D) PCR and densitometric quantification of Acan in C3H10T1/2 cells transfected with ROR2- or scrambled siRNA and cultured in micromass for 3 days, $n=3$. Unpaired t-test, $P=0.023$. (A-D) line at mean, error bars show standard error of the mean. (E) Molecular markers of differentiation and proliferation in $\mathrm{C} 3 \mathrm{H} 10 \mathrm{~T}^{1} / 2$ cells transfected with ROR2- or scrambled siRNA and cultured in micromass for 3 days, $n=4-5$. Box and whiskers plots show all values, line at the median, boxes extend from the 25th to 75th percentiles, error bars span max to min values, unpaired t-test, $\mathrm{P}=0.049$. (F) Adamts -4 and Adamts -5 expression in $\mathrm{C} 3 \mathrm{H} 10 \mathrm{~T}^{1} / 2$ cells expressing ROR2- or control shRNA. Cells were cultured as in (C) and gene expression compared by realtime PCR analysis. $n=3-4$, line at mean, error bars show standard error of the mean, unpaired $t-$ test, Adamts $-4 \mathrm{P}=0.00040$, Adamts $-5 \mathrm{P}=0.0025$. 

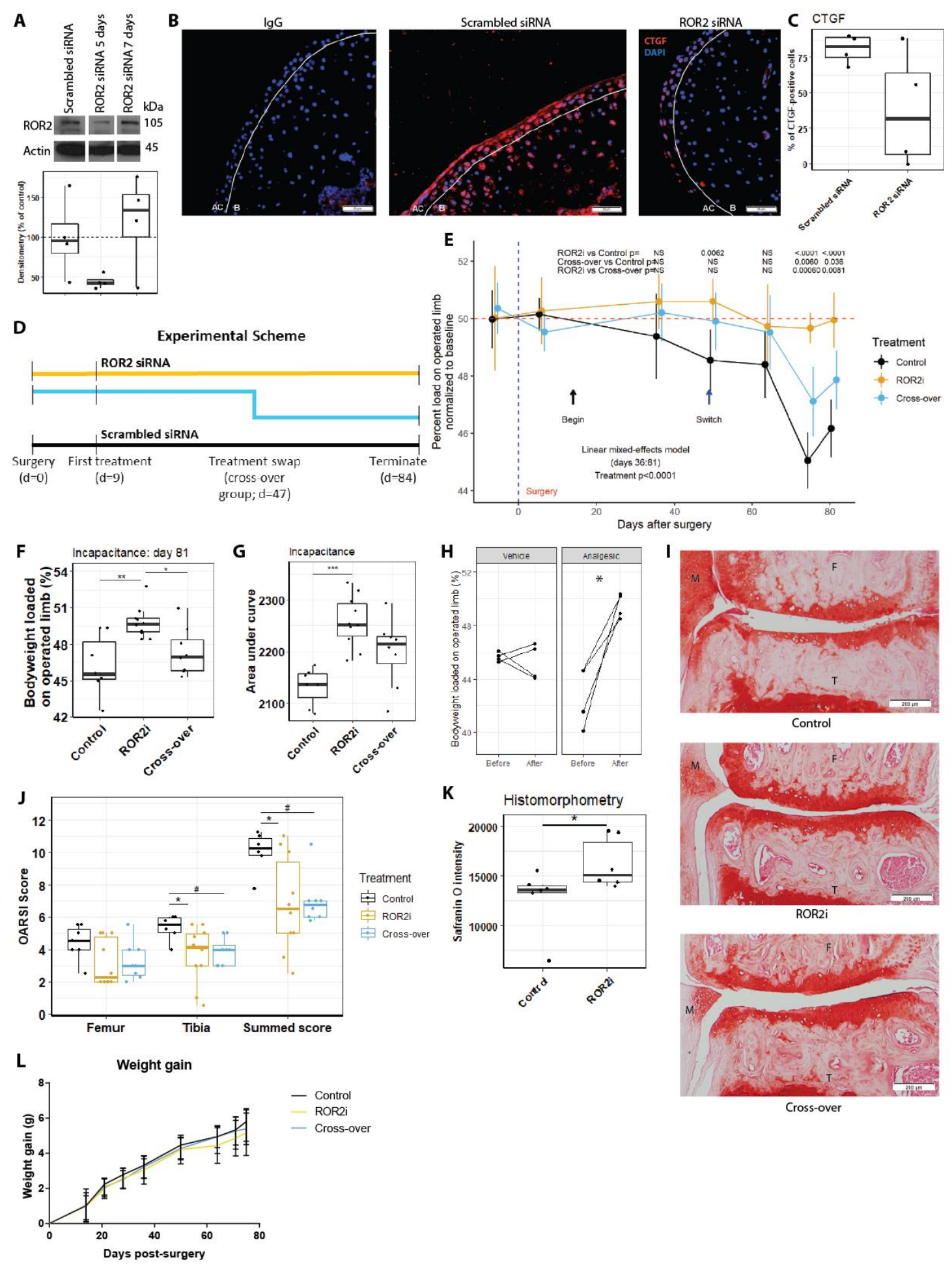

Fig. 4. ROR2 blockade improves pain and structural outcomes of osteoarthritis in mice 
(A) ROR2 expression in the tibia 5 days after intra-articular injection of $20 \mu \mathrm{M}$ ROR2 siRNA conjugated to $0.5 \%$ atelocollagen in mice. Western blot and densitometric quantification, values were normalized for actin, $\mathrm{n}=4$. Images closest to the median are shown, all replicates are in fig. S5. Box and whiskers plots show all values, line at the median, boxes extend from the $25^{\text {th }}$ to $75^{\text {th }}$ percentiles, error bars span max to min values. (B) CTGF expression (red), dapi (blue) in femoral condyles 5 days after intra-articular injection with ROR2- or scrambled siRNA conjugated to $0.5 \%$ atelocollagen in mice. IgG, isotype control; AC, articular cartilage; $\mathrm{B}$, bone; dotted line indicates the osteochondral junction; bars, $50 \mu \mathrm{m}$. (C) The percentage of cells expressing CTGF in the articular cartilage in (B), $n=4$, box and whiskers plots show all values, line at the median, boxes extend from the $25^{\text {th }}$ to $75^{\text {th }}$ percentiles, error bars span max to min values. (D) Experimental scheme. Two weeks after menisco-ligament injury (MLI) surgery, ROR2i or scrambled (control) siRNA was injected intra-articularly for ten weeks; d, day, $\mathrm{n}=7$ (control), 10 (ROR2i), 8 (crossover). (E) Percentage of bodyweight loaded on the operated leg. Blue dotted line indicates surgery, black arrow indicates start of treatment, blue arrow indicates treatment switch for the crossover group. Circles show mean, error bars show 95\% confidence intervals. Mixed effect linear model with pairwise comparisons at the different time points (Tukey correction of P-values for multiple comparisons). P-values at timepoints shown in figure. (F) Incapacitance at day 81 (final time-point). Box and whiskers plots show all values, line at the median, boxes extend from the $25^{\text {th }}$ to $75^{\text {th }}$ percentiles, error bars span max to min values. ANOVA with Tukey's HSD post-hoc test, control vs ROR2i $\mathrm{P}=0.0030$, ROR2i vs crossover $\mathrm{P}$ $=0.036$. $(\mathbf{G})$ The area under the curve of incapacitance was calculated starting from day 35. Box and whiskers plots show all values, line at the median, boxes extend from the $25^{\text {th }}$ to $75^{\text {th }}$ percentiles, error bars span max to min values. ANOVA with Tukey's HSD post-hoc test, control 
vs ROR2i $\mathrm{P}=0.00019$. (H) Incapacitance was measured before, and $1 \mathrm{hr}$ after administration of $0.1 \mathrm{mg} / \mathrm{kg}$ buprenorphine (analgesic) or saline (vehicle), $\mathrm{n}=4$, all data points shown, lines connect paired samples. Mann-Whitney U test, $\mathrm{P}=0.016$. (I) Representative images of Safranin O staining of the medial compartment; F, Femur; T, Tibia; M, Meniscus; bars, $200 \mu \mathrm{m}$. (J) Osteoarthritis severity was assessed using the Osteoarthritis Research Society International (OARSI) scoring system. Box and whiskers plots show all values, line at the median, boxes extend from the $25^{\text {th }}$ to $75^{\text {th }}$ percentiles, error bars span max to min values. Kruskal-Wallis with Dunn's post-test and Benjamini-Hochberg multiple correction, Tibia $* \mathrm{P}=0.031, \# \mathrm{P}=0.040$, Summed * $\mathrm{P}=0.041, \# \mathrm{P}=0.031$. $(\mathbf{K})$ Quantification of structural integrity and proteoglycan content of the articular cartilage, assessed by histomorphometrical analysis. Box and whiskers plots show all values, line at the median, boxes extend from the $25^{\text {th }}$ to $75^{\text {th }}$ percentiles, error bars span max to min values. Mann-Whitney $\mathrm{U}$ test, $\mathrm{P}=0.026$. (L) Weight gain of mice over 10 weeks of treatment with ROR2i, error bars show standard error of the mean. 


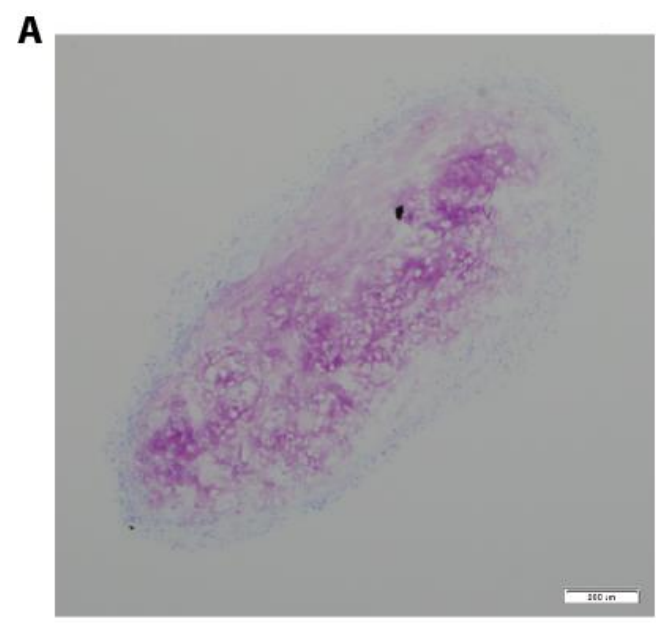

shControl

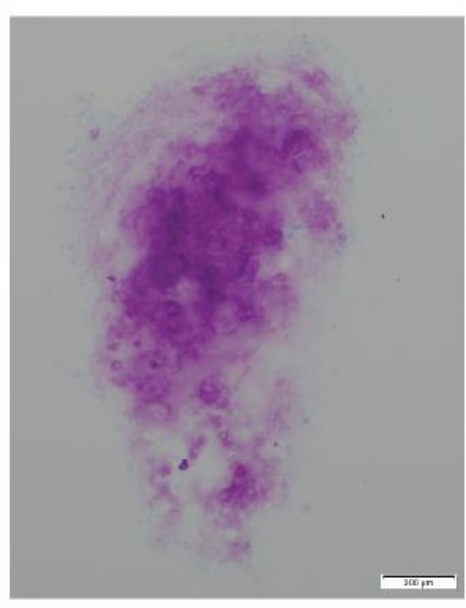

shROR2

\section{B Differentiated area of cartilage organoids}

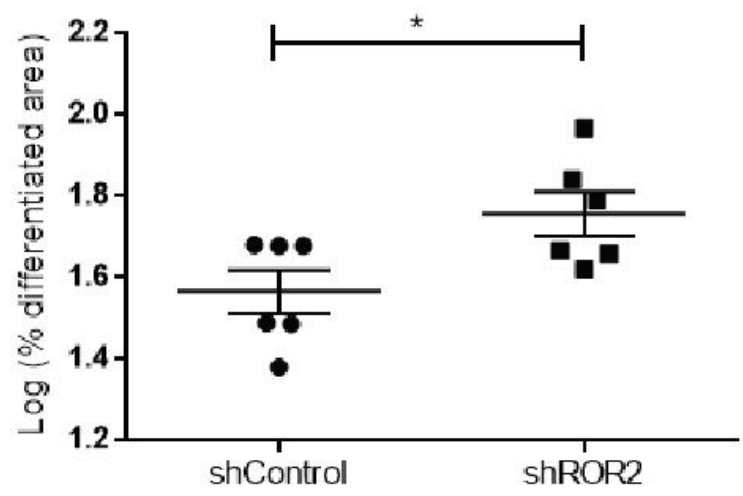

\section{Fig. 5. ROR2 blockade enhances human cartilage formation in vivo}

Human articular chondrocytes were transduced with ROR2 or control shRNA and implanted subcutaneously in the backs of nude mice. Two weeks later, cartilage implants were retrieved. (A) Toluidine blue staining of cartilage-specific highly sulphated glycosaminoglycans (purple) in the implants. Images closest to the median are shown, bars, $200 \mu \mathrm{m}$. (B) Histomorphometric analysis of the differentiated area normalized for total area, $\mathrm{n}=6$, line at mean, standard error of the mean, unpaired t-test, $\mathrm{P}=0.031$. 

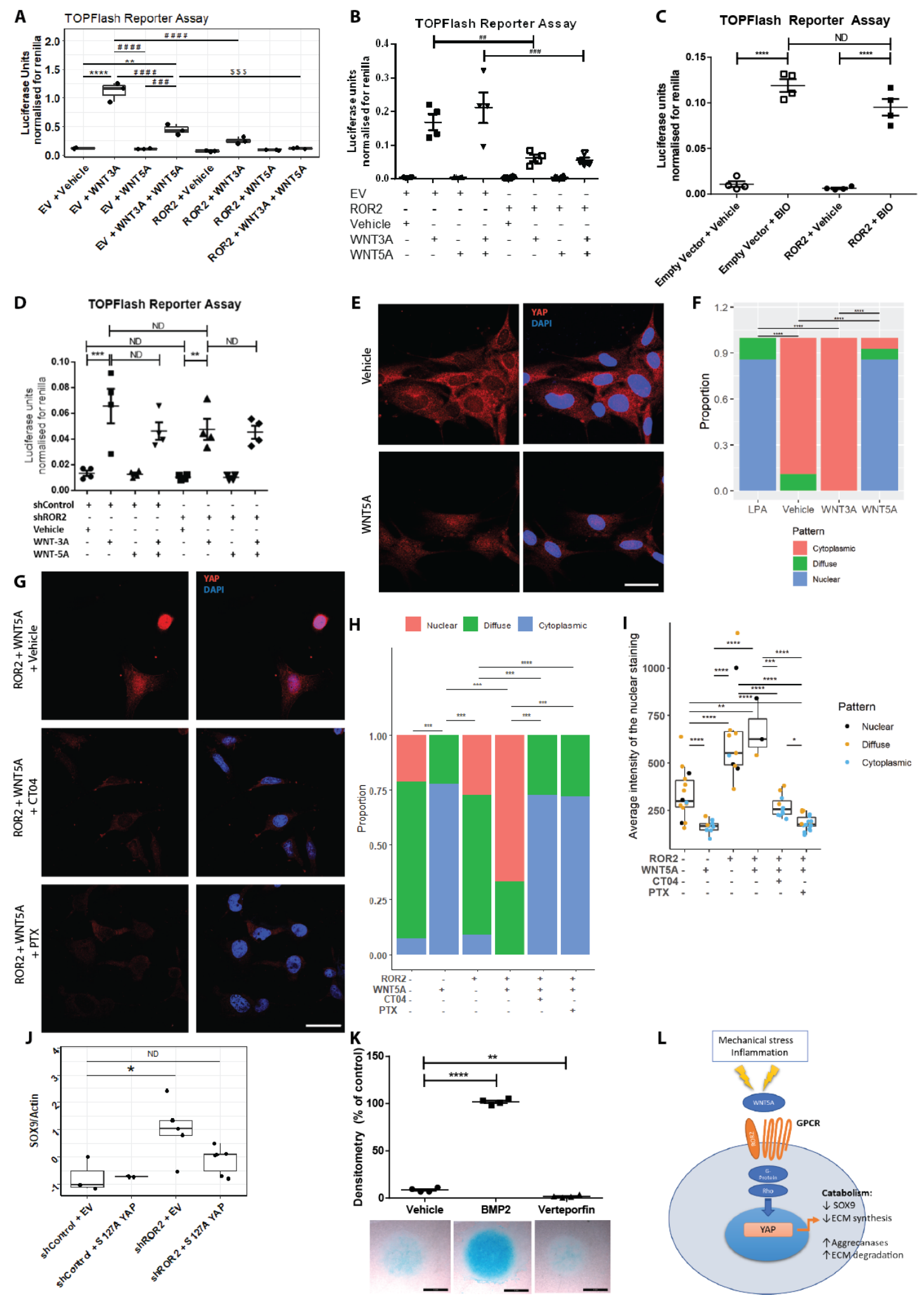

Fig. 6. ROR2 blockade increases chondrogenic differentiation through YAP 
TOPFlash reporter assay in (A) HEK293 cells transfected with an empty vector (EV) or ROR2 and stimulated with $100 \mathrm{ng} / \mathrm{mL}$ WNT3A, WNT5A, both or vehicle. Box and whiskers plots show all values, line at the median, boxes extend from the $25^{\text {th }}$ to $75^{\text {th }}$ percentiles, error bars span max to min values. $\mathrm{n}=4$, ANOVA with Tukey's HSD post-hoc test, ${ }^{* *} \mathrm{P}=0.0011$, \#\#\# $\mathrm{P}=$

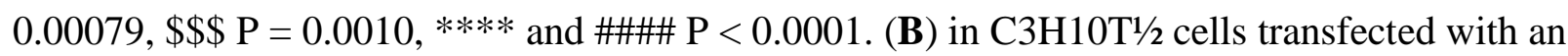
empty vector (EV) or ROR2 and stimulated with $100 \mathrm{ng} / \mathrm{mL}$ WNT3A, WNT5A, both or vehicle. (C) in $\mathrm{C} 3 \mathrm{H} 10 \mathrm{~T}^{1} / 2$ cells transfected with an empty vector or ROR2 and stimulated with $5 \mu \mathrm{M}$ BIO or vehicle and (D) in C3H10T1/2 cells expressing shControl or shROR2 and stimulated with 100 ng/mL WNT3A, WNT5A, both or vehicle. (B-D) $n=4$, line at mean, error bars show standard error of the mean, 2-way ANOVA with Tukey's HSD post-hoc test, \#\# $\mathrm{P}=0.010$, \#\#\# $\mathrm{P}=$ $0.0001, * * * * \mathrm{P}<0.0001, * * * \mathrm{P}=0.0001, * * \mathrm{P}=0.0081, \mathrm{ND}=$ no significant difference. $(\mathbf{E})$ Immunofluorescence for YAP (red) in C3H10T1/2 cells stimulated with $100 \mathrm{ng} / \mathrm{mL}$ WNT5A or vehicle for 4 hours, dapi (blue), bars, $50 \mu \mathrm{m}$. (F) Quantification of the proportion of cells with prevalent nuclear, diffuse, or cytoplasmic staining. Individual cells were given a score of 0 (cytoplasmic), 1 (diffuse), or 2 (prevalently nuclear) and a generalized linear model was fit to compare the groups followed by a post-hoc pairwise comparison (Tukey correction), $* * * * \mathrm{P}<$ 0.0001 for all comparisons. 7-18 cells per condition were scored. (G) Immunofluorescence for YAP (red) in C28I/2 cells transfected with empty vector or ROR2, pre-treated with $2 \mu \mathrm{g} / \mathrm{mL}$ CT04, $100 \mathrm{ng} / \mathrm{mL}$ PTX or vehicle for 2 hours and stimulated with inhibitors and $100 \mathrm{ng} / \mathrm{mL}$ WNT5A for 4 hours, dapi (blue), bars, $50 \mu \mathrm{m}$. (H) Quantification of the proportion of cells with prevalent nuclear, diffuse, or cytoplasmic staining. 3-18 cells per condition were scored. Individual cells were given a score of 0 (cytoplasmic), 1 (diffuse), or 2 (prevalently nuclear) and a generalized linear model was fit to compare the groups followed by a post-hoc pairwise 
comparison (Tukey correction). Vehicle vs WNT5A P =0.0003, WNT5A vs ROR2 P =0.0004, WNT5A vs ROR2 + WNT5A P = 0.0003, ROR2 vs ROR2 + WNT5A + CT04 P = 0.0004, ROR2 vs ROR2 + WNT5A + PTX P $<0.0001$, ROR2 + WNT5A vs ROR2 + WNT5A +CT04 P $=0.0003$, ROR2 + WNT5A vs ROR2 + WNT5A + PTX P $=0.0002,($ I $)$ Intensity of YAP staining within the nucleus in $\mathrm{C} 28 \mathrm{I} / 2$ cells treated as in $(\mathrm{G}), \mathrm{n}=3-18$, box and whiskers plots show all values, line at the median, boxes extend from the $25^{\text {th }}$ to $75^{\text {th }}$ percentiles, error bars span max to min values. ANOVA with TukeyHSD post-hoc test on logged values, $* \mathrm{P}=0.012$, ** $\mathrm{P}=$ 0.0015, *** $\mathrm{P}=0.00012, * * * * \mathrm{P}<0.0001$. (J) C3H10T1/2 cells expressing shROR2 or control shRNA were transfected with an empty vector (EV) or S127A YAP (constitutively active YAP) and cultured in micromass for 3 days. Gene expression was compared by real-time PCR analysis, data from two independent experiments were scaled and combined. Box and whiskers plots show all values, line at the median, boxes extend from the $25^{\text {th }}$ to $75^{\text {th }}$ percentiles, error bars span max to min values. Two-way ANOVA with Tukey's HSD post-hoc test. $\mathrm{P}=0.024, \mathrm{ND}=$ no significant difference. (K) C3H10T1/2 cells were cultured in micromass for 3 days with $100 \mathrm{ng} / \mathrm{ml}$ BMP2, $7 \mu \mathrm{M}$ Verteporfin (YAP inhibitor), or vehicle. Micromasses were stained with Alcian blue and compared by densitometry. Representative images are shown below, bars $2 \mathrm{~mm}, \mathrm{n}=4$, line at mean, error bars show standard error of the mean. ANOVA with Tukey's HSD post-hoc test, $* * \mathrm{P}=0.0070, * * * * \mathrm{P}<0.0001$. (L) ROR2 signaling after cartilage injury: WNT5A activates ROR2, which, through the co-operation of G-protein coupled receptors (GPCR) and Rho, induce nuclear localization of YAP and activate catabolic signaling. ECM, extracellular matrix. 


\section{Supplementary Methods}

\section{Histomorphometrical analysis of cartilage}

Safranin O staining was carried out in batches at random, across treatment groups. All images were taken using the same settings and exposure, with any auto-enhancing features of the camera and of the acquisition program turned off, which, by normalizing the total luminosity and contrast, or modifying the colours, might reduce the differences and therefore lead to falsenegative results.

A global scale was set in ImageJ using the scale bar. Each image was then opened in ImageJ (fig. S12A) and rotated so that a line drawn along the cartilage-bone junction in the middle of the plateau is perfectly horizontal (fig. S12B). This is very important so that non-cartilage staining in the bone marrow spaces can be eliminated (see below). This was accomplished by drawing a line with the line tool and noting the angle as doing so. The image was then rotated by this angle. Then, the tibial plateau was selected using a polygon or free-hand tool, including any osteophytes, the growth plate and up to the end of the cartilage (fig. S12C). The selection was copied, and all sections placed on a single large canvas, aligned horizontally (fig. S12D). To isolate the metachromatic Safranin O staining from the background and most of the orthochromatic staining (subchondral bone) the RGB image was transformed into a hue, saturation, brightness (HSB) stack (Image> Type>HSB Stack), and the "Saturation" slice selected. This abolishes background and staining of the bone (fig. S12E).

Setting the region of interest (fig. S12E): a rectangle 600 microns wide and the full height of the canvas was made. The rectangle was placed over the first section to include the tibial plateau, making sure to exclude any osteophyte (left side in this figure) and the "bulgy" part near the 
intercondylar notch. Osteophytes are best identified in the original figure rather than in the "Saturation" slice. Press Ctrl+1. Slide the rectangle laterally over the next section and press $\mathrm{Ctrl}+2$. This was done for each section and, when over the last section, $\mathrm{Ctrl}+3$ were pressed. This plots the density profile of each section (fig. S12F). The first negative peak is the articular cartilage.

One horizontal line was drawn to cut the residual background, if any, and lateral lines to limit the articular cartilage peak (fig. S12G) and eliminate the staining of the bone marrow spaces. This was repeated for each profile of the sections in the same canvas. Using the "Wand" tool and clicking inside the area under the curve in each of the density profiles highlighted the area under the curve and returned the area measurement. These results were copied from the measurements box into a statistics programme to calculate the median. The median of all the sections of each knee was utilised for that individual knee.

Sections with cutting or staining artefacts (understained or saturated) were excluded, and knees with less than 3 intact sections were excluded. For optimum consistency there should be 4-6 sections covering 200 microns around the centre of the tibial plateau. The central section is identified as the one with the shortest cross section of the medial meniscus. R script for further analysis can be supplied upon request.

\section{Subchondral bone measurement}

Ensuring that a global scale had been set for all images, using the rotated image (fig. S12B), five measurements of the subchondral bone were taken. Measurements were taken perpendicular to the cartilage-bone junction and went to the top of bone marrow, or if there was no bone marrow, to the growth plate (fig. S12H). Analyse > Measure returned the length of the lines (fig. S12I). 
These results were copied from the measurements box into a statistics programme to calculate the mean subchondral bone thickness (microns) for each image. The mean of all images from each knee was utilised for that individual knee. Subchondral bone thickness was measured from at least 3 sections of each knee.

$\mathrm{R}$ script for further analysis can be supplied upon request.

\section{Synovium measurement}

In a similar way as for the subchondral bone and as described by Valverde-Franco et al., ensuring that a global scale had been set, synovial thickness was measured by drawing a line that went horizontally through the synovial lining (fig. S12J). Analyse > Measure returned the length of the lines. These results were copied from the measurements box into a statistics programme to calculate the mean synovial thickness (microns) for each image. The mean of all images from each knee was utilised for that individual knee. Synovial thickness was measured from at least 3 sections of each knee.

$\mathrm{R}$ script for further analysis can be supplied upon request.

\section{Osteophyte measurement}

Ensuring that a global scale had been set for all images, using the rotated image (fig. S12B), medial tibial osteophytes were selected with the polygon or free-hand tool (fig. S12K). Having set the measurements to include Area and Perimeter, Analyse > Measure returned these parameters. These results were copied from the measurements box into a statistics programme to calculate the mean area and perimeter of the osteophyte (in microns) for each image. The mean 
of all images from each knee was utilised for that individual knee. Osteophytes from at least 3 sections of each knee were measured.

$\mathrm{R}$ script for further analysis can be supplied upon request.

\section{Quantification of Toluidine Blue staining}

Using Toluidine Blue at $\mathrm{pH} 4$, cartilage ECM is stained purple, and other tissue elements are blue. Brightfield images were taken using the same settings on an Olympus BX61 microscope. The total area of the explant (blue) and differentiated area (purple) were selected using the "magic wand" tool of the Cell Sense software (Olympus) (fig. S13). The \% differentiated area was calculated by: Differentiated area $\div$ total area $x 100$ For each implant, 2-3 sections were analysed and the one with the largest total area was considered the central part of the implant and included in the analysis. 


\section{Supplementary Figures and Tables}

A

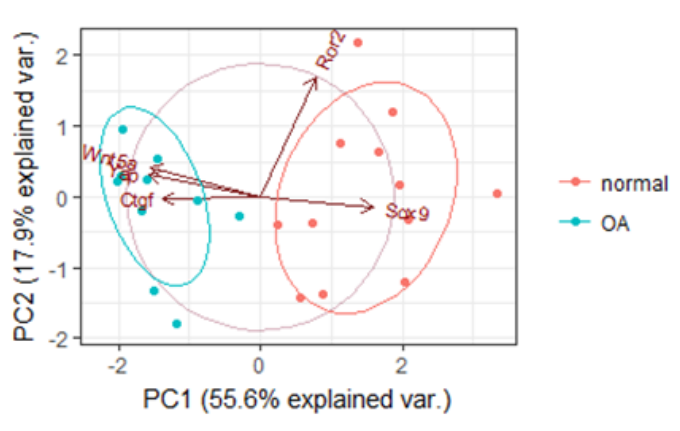

B

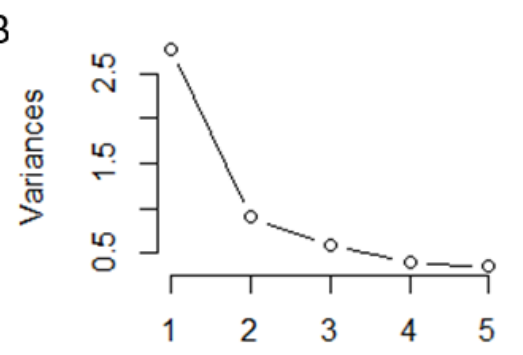

C Standard deviations $(1, \ldots, p=5)$ :

[1] $1.6668285 \quad 0.9461762 \quad 0.7645520 \quad 0.6237890 \quad 0.5939537$

Rotation $(\mathrm{n} \times \mathrm{k})=(5 \times 5)$ :

$\begin{array}{lrrrrr} & \text { PC1 } & \text { PC2 } & \text { PC3 } & \text { PC4 } & \text { PC5 } \\ \text { Ror2 } & 0.2474543 & 0.953823041 & -0.1477087 & 0.05555768 & 0.06390195 \\ \text { Wnt5a } & -0.4919125 & 0.232105363 & 0.3656911 & 0.04552187 & -0.75388789 \\ \text { Ctgf } & -0.4382980 & -0.009377399 & -0.8838824 & -0.06474668 & -0.14955485 \\ \text { Yap } & -0.4982965 & 0.173863334 & 0.2206342 & -0.68964735 & 0.44404860 \\ \text { Sox9 } & 0.5063436 & -0.077667968 & -0.1205178 & -0.71765974 & -0.45609623\end{array}$

Importance of components\%s:

$\begin{array}{llllll}\text { PC1 } & \text { PC2 } & \text { PC3 } & \text { PC4 } & \text { PC5 }\end{array}$

$\begin{array}{llllll}1.6668 & 0.9462 & 0.7646 & 0.62379 & 0.59395\end{array}$

Proportion of Variance $0.5557 \quad 0.1790 \quad 0.1169 \quad 0.07782 \quad 0.07056$

Cumulative Proportion $0.5557 \quad 0.7347 \quad 0.8516 \quad 0.92944 \quad 1.00000$

$>$ d.pca

Standard deviations $(1, \ldots, p=5)$ :

$\begin{array}{llllllll}\text { [1] } & 1.6668285 & 0.9461762 & 0.7645520 & 0.6237890 & 0.5939537\end{array}$
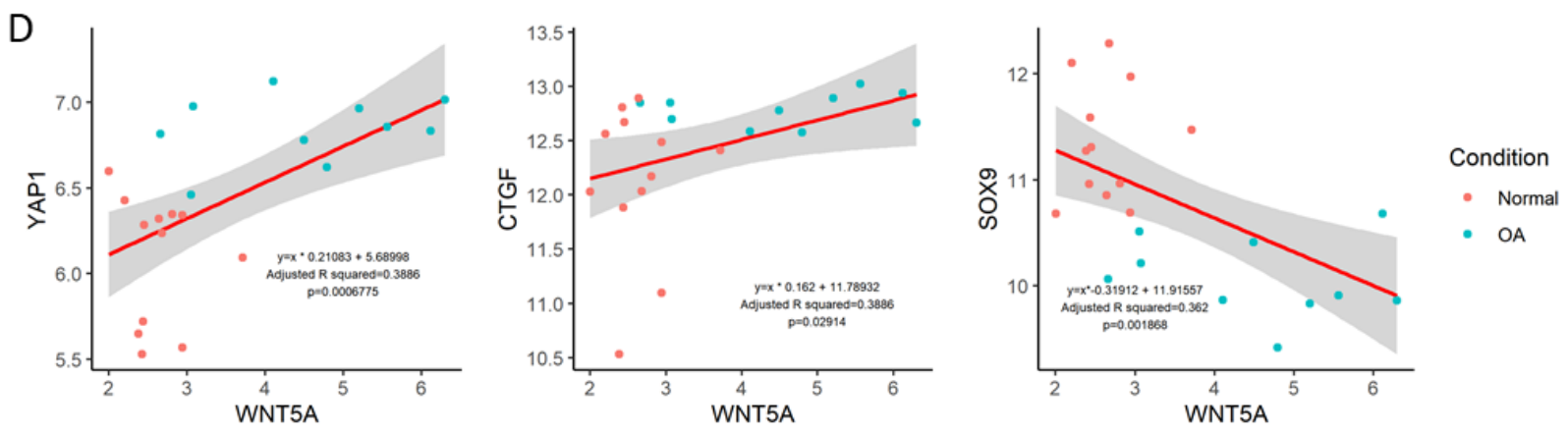

Fig. S1. Relationship between ROR2, WNT5A, YAP, CTGF and SOX9 in in human

osteoarthritic cartilage and healthy normal cartilage (29). n=12. (A) Biplot of principal

component (PC) analysis. Var, variance. (B) Variance contributed by each PC. (C) Contribution of ROR2, WNT5A, CTGF, YAP and SOX9 to each PC and importance of each PC. (D) 
Correlation between YAP and WNT5A, Pearson test for correlation and a linear regression shown by red line. Grey area indicates $95 \%$ confidence, $\mathrm{r}^{2}=0.39, \mathrm{P}=0.00068$; CTGF and WNT5A, $\mathrm{r}^{2}=0.39, \mathrm{p}=0.029 ;$ SOX9 and WNT5A, $\mathrm{r}^{2}=0.36, \mathrm{P}=0.0019$. 
A

$\lg G$

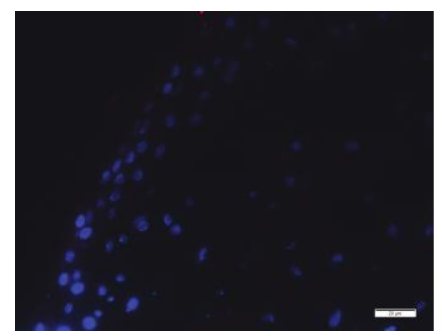

B

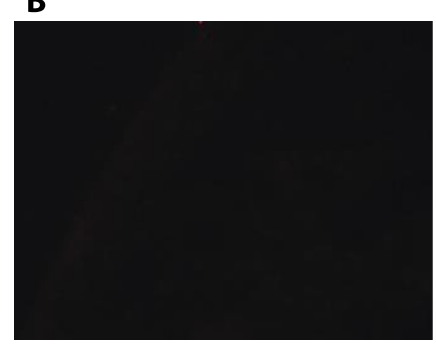

c

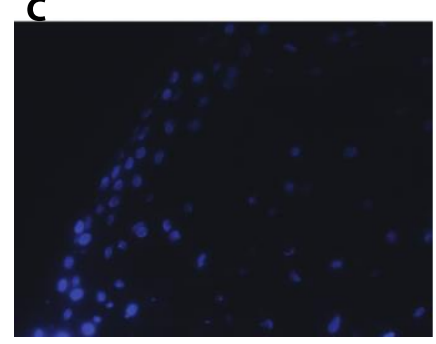

D

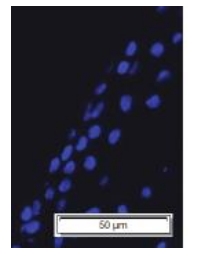

ROR2: 0 days
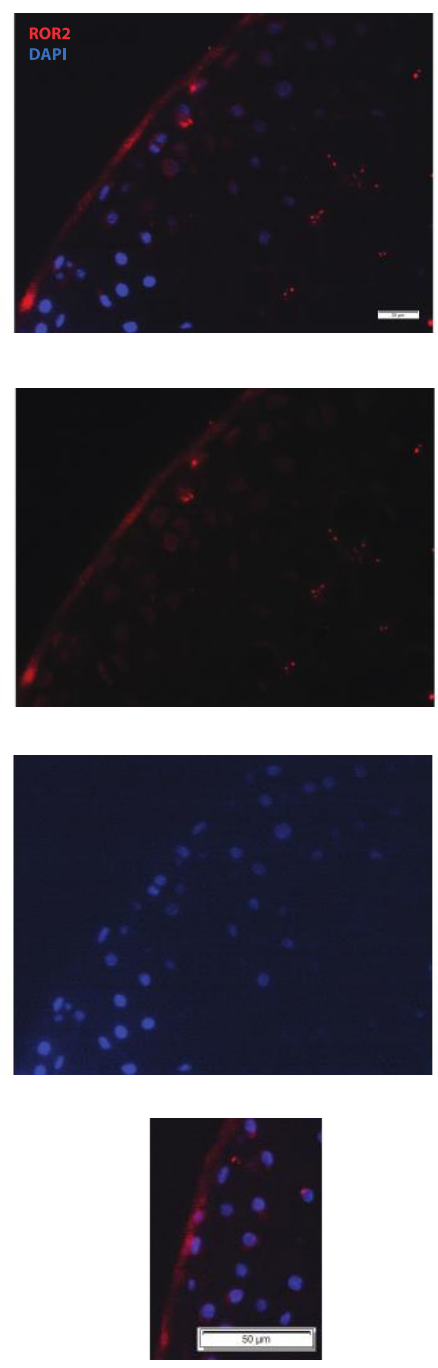

ROR2: 1 day
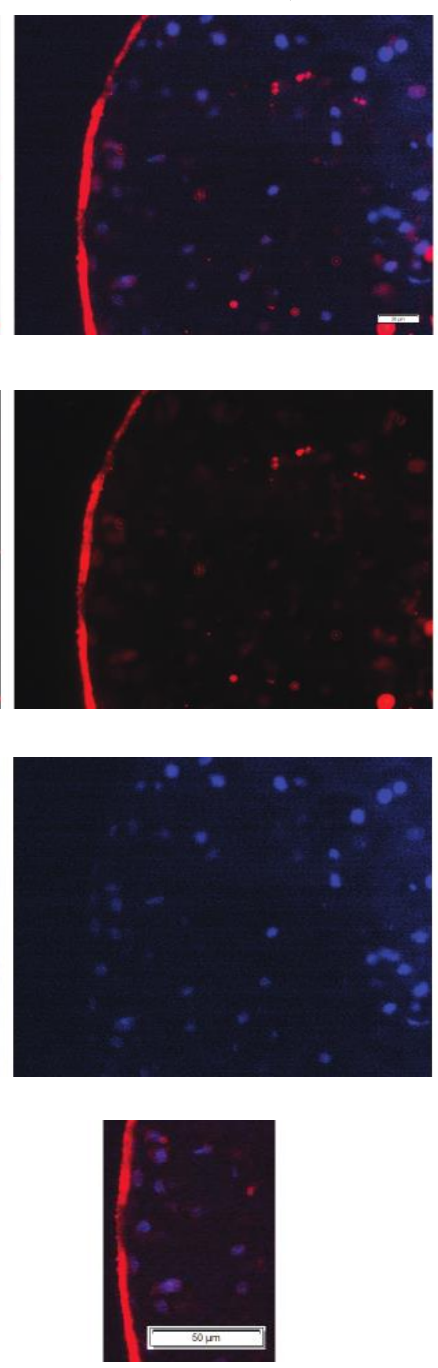

ROR2: 7 days
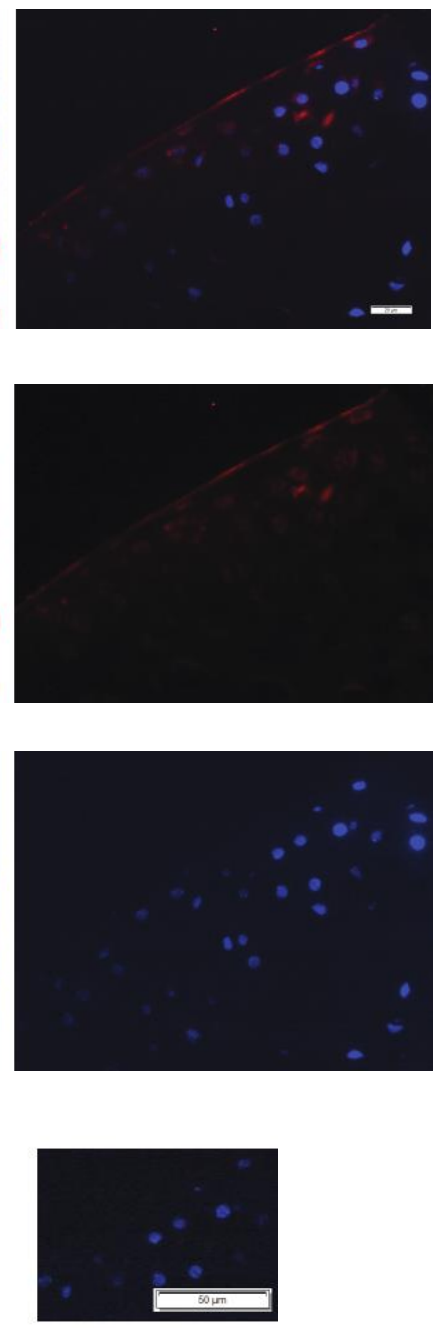

Fig. S2. ROR2 immunostaining in murine femoral head cartilage at 0,1 and 7 days after explantation (columns 2-4). Non-immune IgG (isotype) control in column 1. n= 7 (0 days), 4 (1 day) and 3 (7 days). (A) superimposed images with ROR2 (red) and dapi (blue), bars, $20 \mu \mathrm{m}$. (B) Isolated red layer (ROR2) used for quantification. (C) isolated DAPI layer. (D) is higher magnification of (A). Bars, $50 \mu \mathrm{m}$. 
A

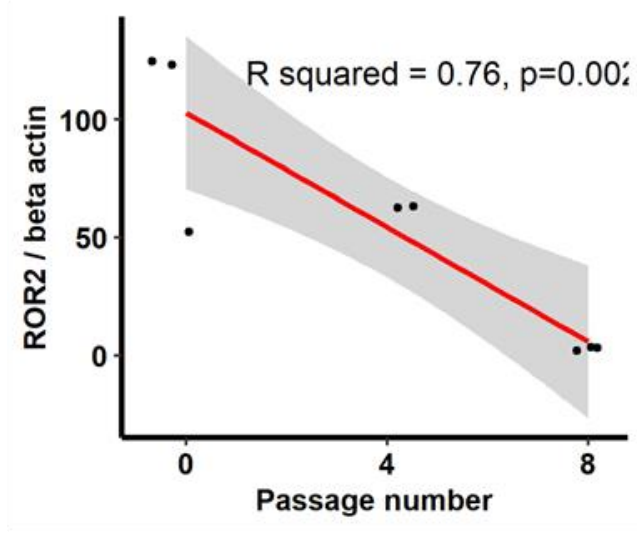

C

Synovial Membrane MSCs:ROR2

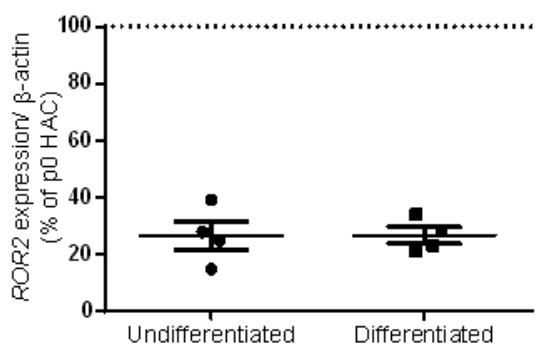

B ROR2

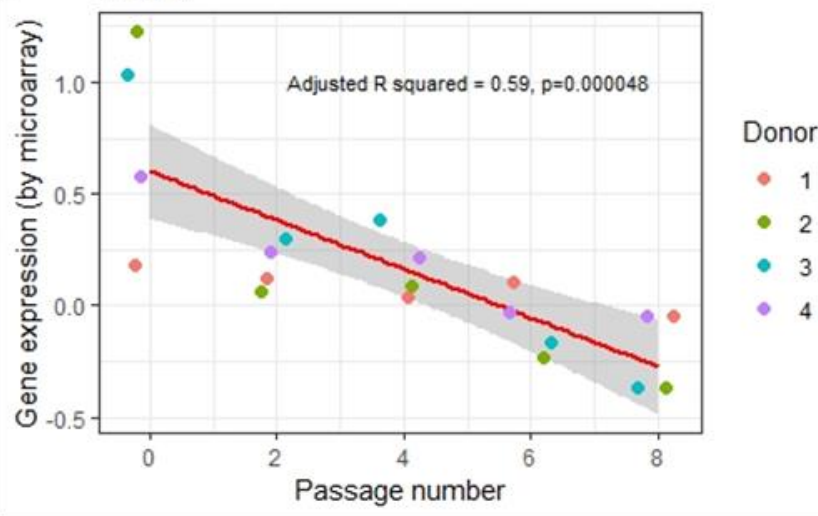

D

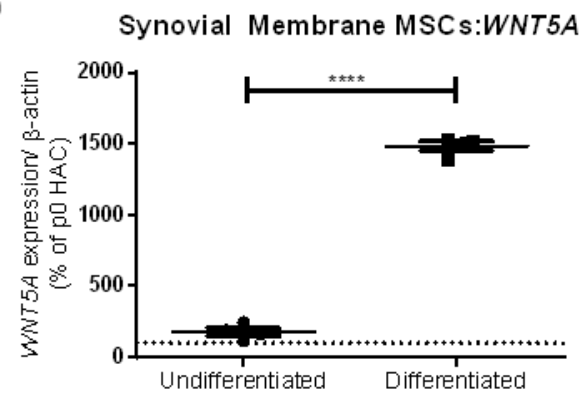

Fig. S3. ROR2/WNT5A expression correlates with chondrocytic differentiation

ROR2 expression in human articular chondrocytes (HAC) between passage 0 and passage 8 as assessed by (A) RT-PCR, n=2-3 patients, 3 technical replicates per patient. Pearson test for correlation and a linear regression shown by red line. Grey area indicates $95 \%$ confidence, $\mathrm{r}^{2}=$ $0.76, \mathrm{P}=0.0029$ and $(\mathbf{B})$ by microarray (GEO Accession GSE42235), $\mathrm{n}=4, \mathrm{r}^{2}=0.59, \mathrm{P}=$ 0.00048. (C) ROR2 and WNT5A expression in synovial membrane mesenchymal stem cells (MSCs) differentiated with $10 \mathrm{ng} / \mathrm{mL}$ TGF- $\beta$ for 6 days in micromass culture. ROR2 and WNT5A expression are presented relative to expression in passage 0 human articular chondrocytes (p0 HAC- dotted line), $\mathrm{n}=4$, line at mean, standard error of the mean, unpaired t-test, $\mathrm{P}<0.0001$. 

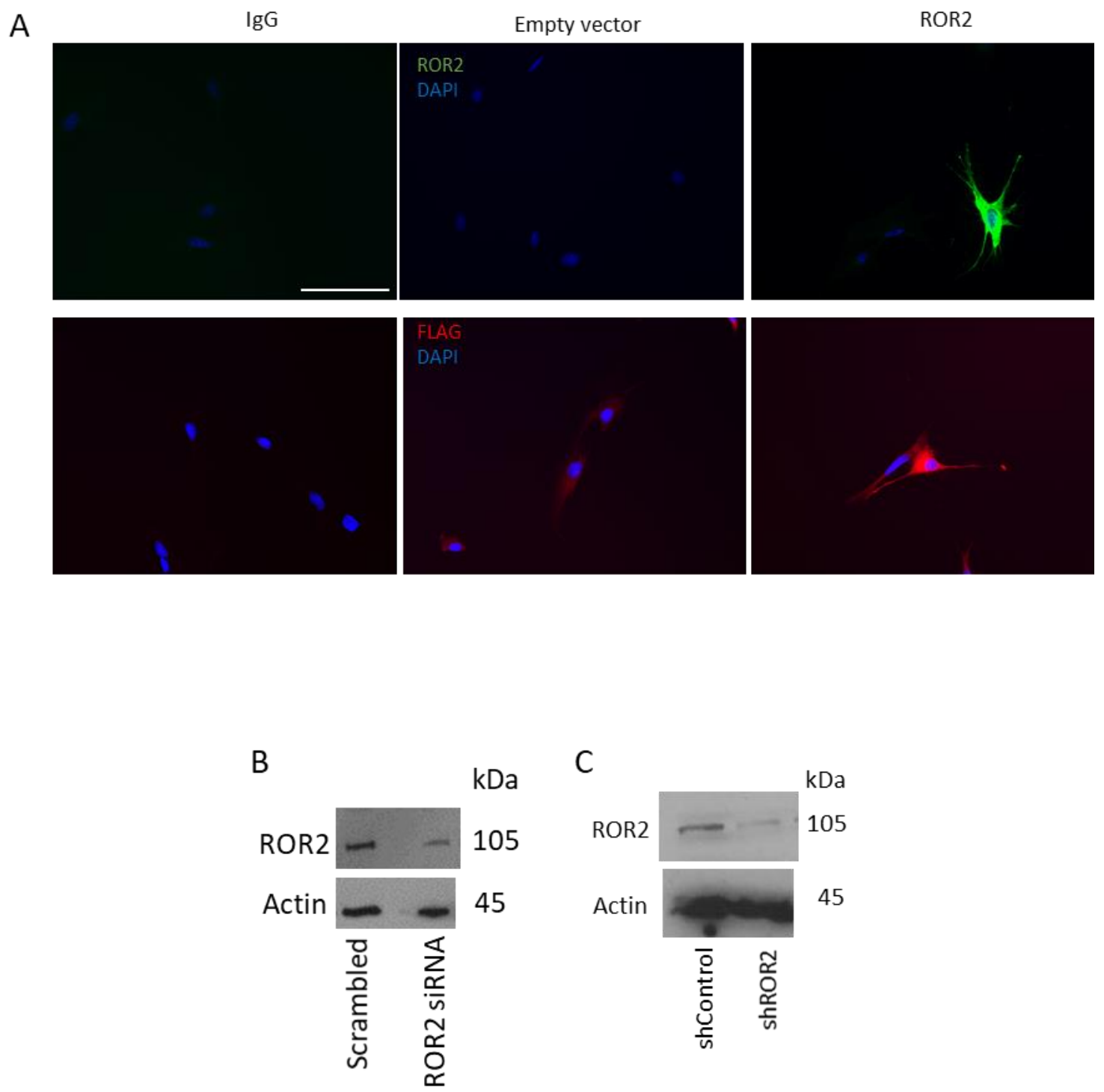

Fig. S4. ROR2 overexpression and silencing efficacy of ROR2 siRNA and shRNA

(A) immunofluorescence staining of ROR2 (green) or FLAG (red) in C3H10T1/2 cells

transfected with empty vector or ROR2, 24 hours after transfection. IgG, non-immune isotype control, dapi (blue), bars, $100 \mu \mathrm{m}$. (B) Western blot showing ROR2-silencing efficiency of ROR2 siRNA in C3H10T1/2 cells, with scrambled siRNA as control. $n=1$. (C) Western blot showing ROR2-silencing efficiency of lentiviral ROR2 shRNA in C3H10T1² cells, non-targeting shControl as control. $\mathrm{n}=1$. 

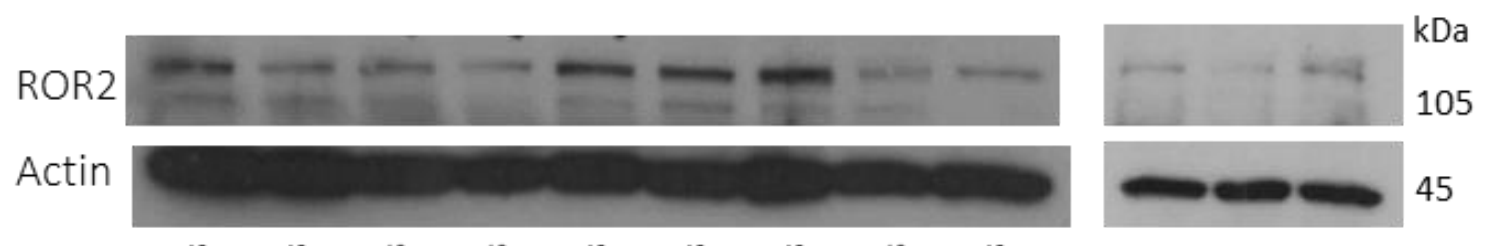

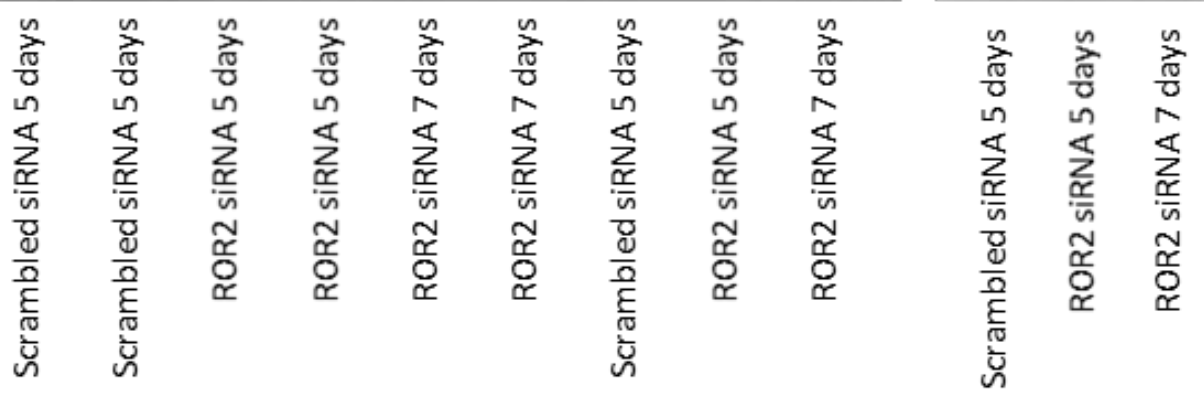

Fig. S5. Silencing efficiency of atelocollagen conjugated ROR2 siRNA in vivo. Western blotting from mouse tibial plateaus, $n=4$. 

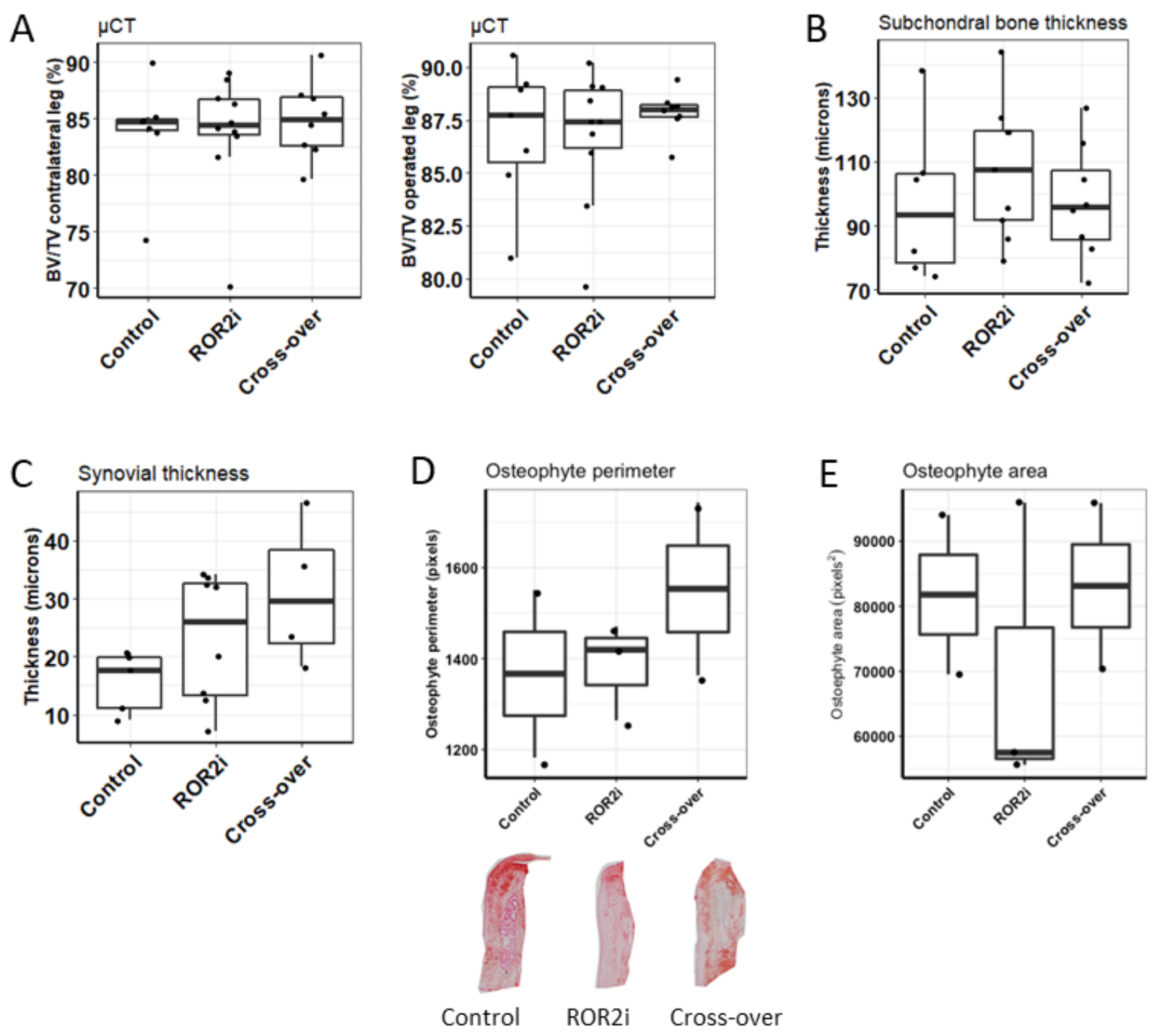

Fig. S6. Treatment with ROR2i in the MLI model of osteoarthritis in mice (A) Bone volume fraction (BV/TV) of medial tibial subchondral plate was measured by $\mu \mathrm{CT}$. (B) Histomorphometrical measurement of medial tibial subchondral bone thickness, (C) synovial lining thickness, (D) osteophyte perimeter and (E) osteophyte area. Representative images of osteophytes are shown below (D). $n=2-10$, box and whiskers plots show all values, line at the median, boxes extend from the $25^{\text {th }}$ to $75^{\text {th }}$ percentiles, error bars span max to min values. 
A
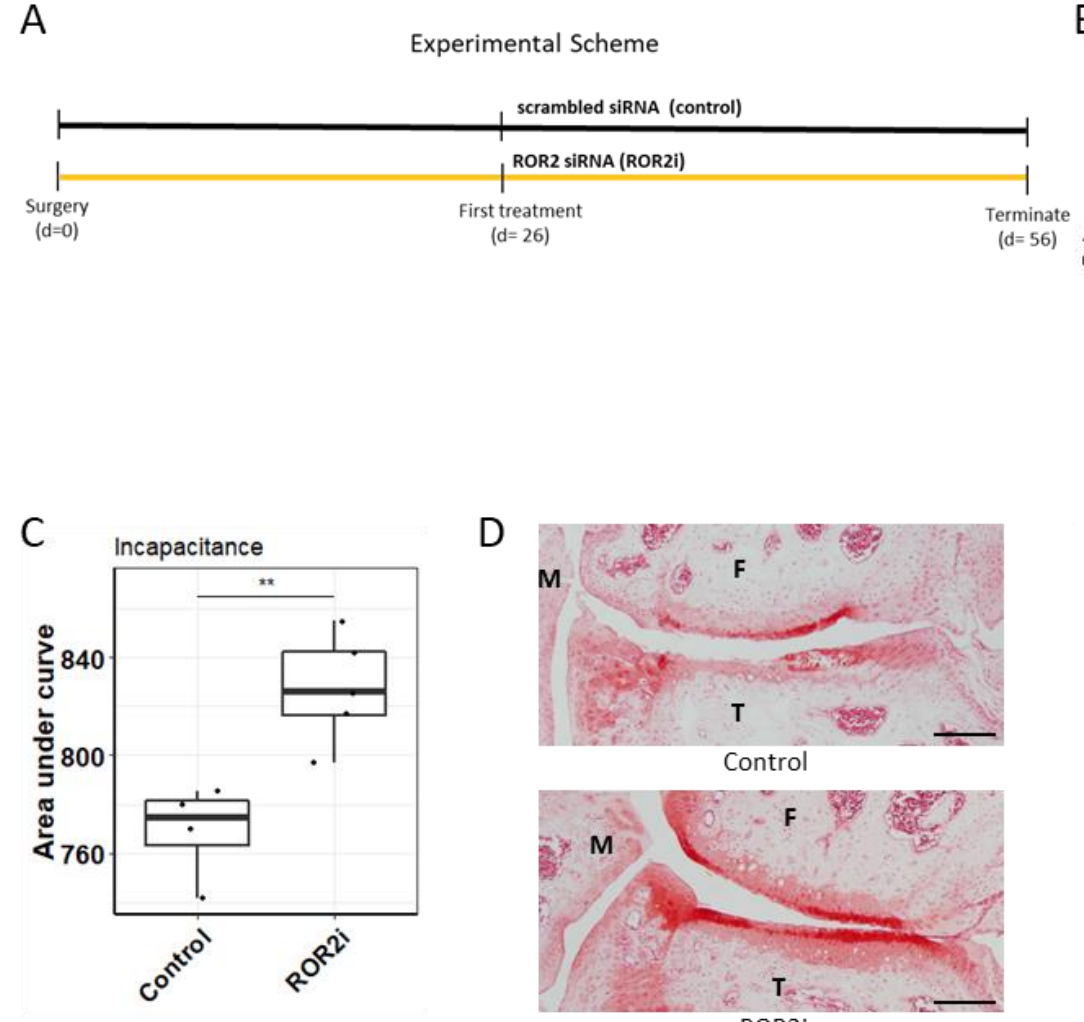

D
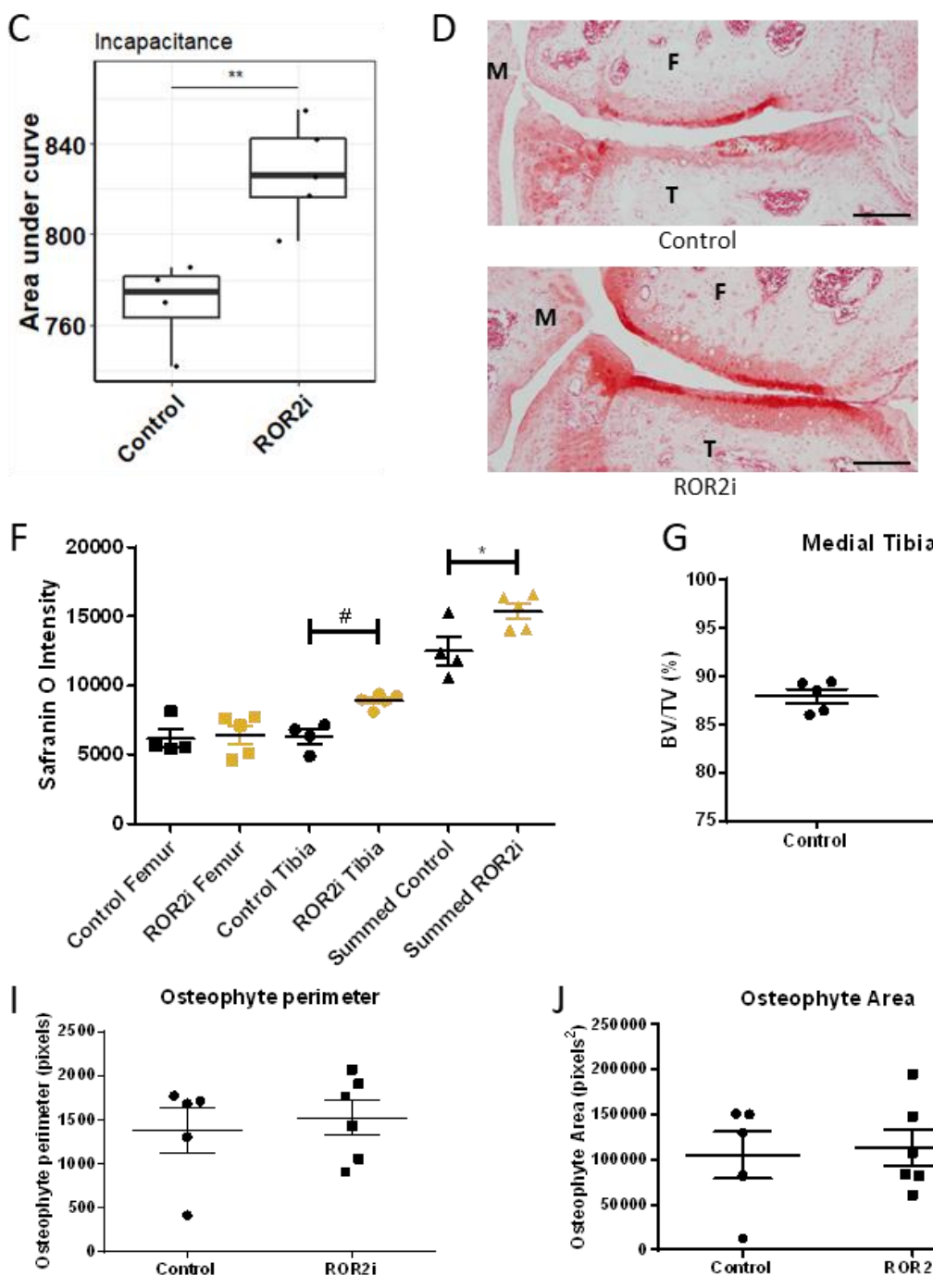
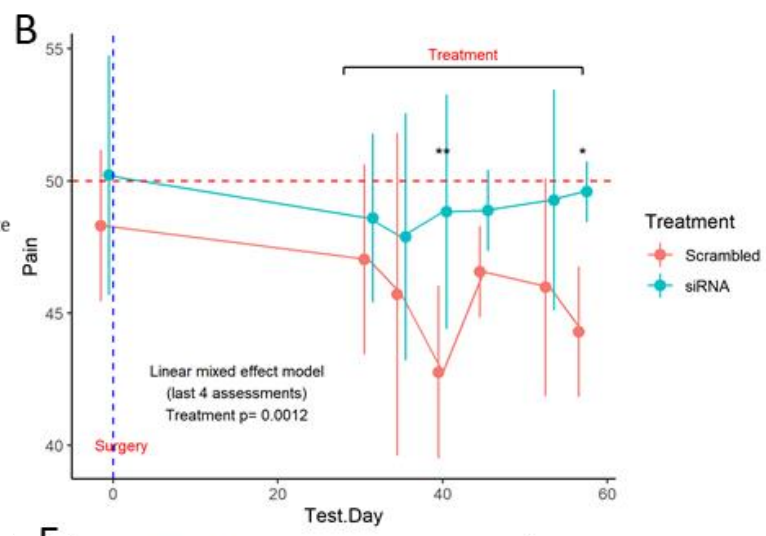

$\mathrm{E}$

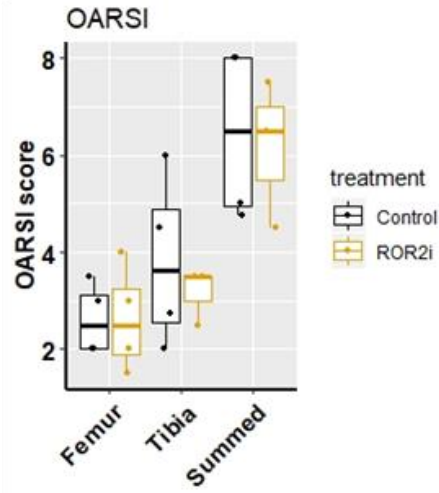

G Medial Tibia BV/TV

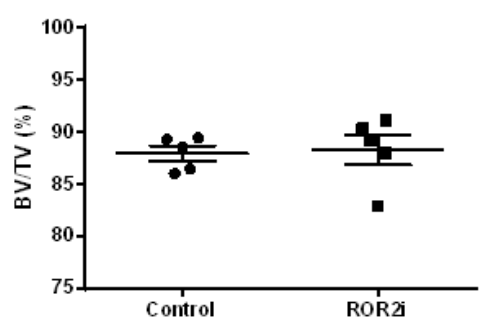

$\mathrm{H}$ Subchondral Bone Thickness
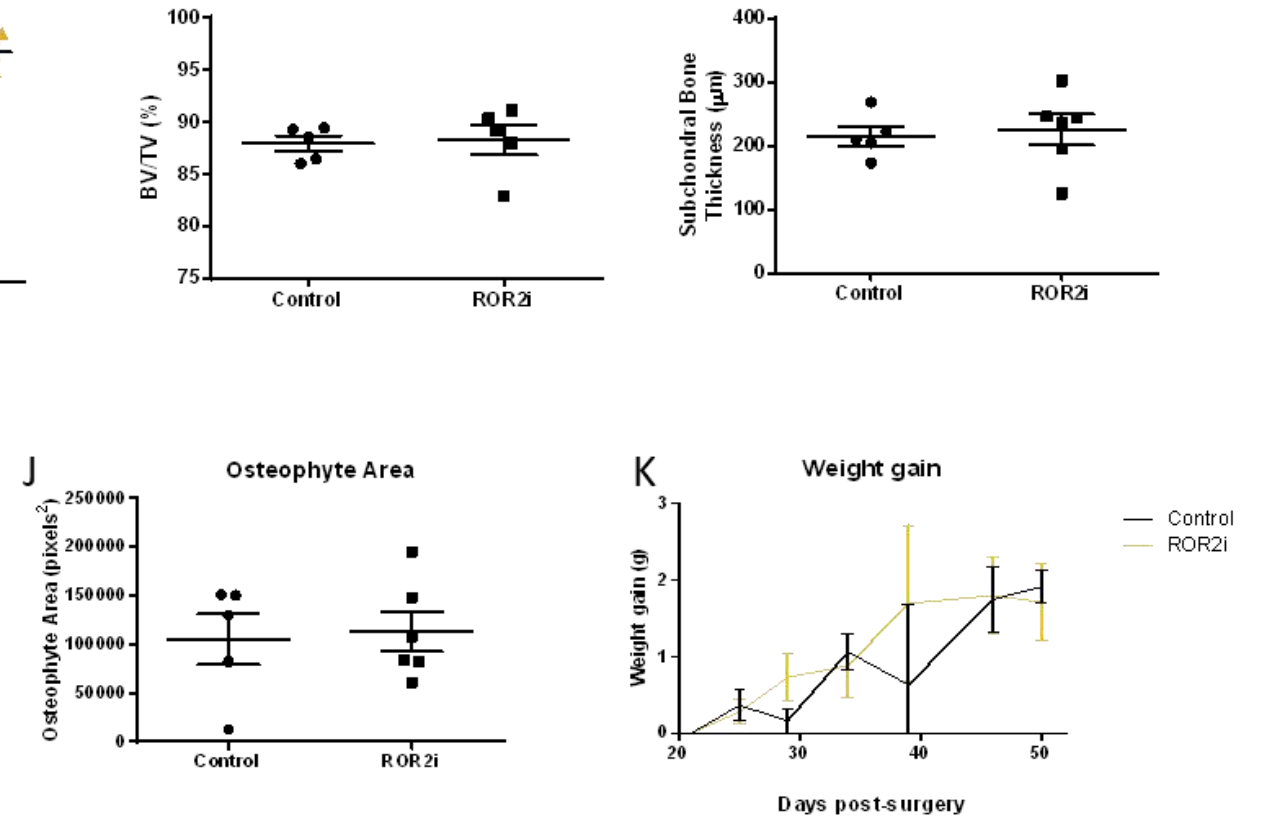

Fig. S7. Four weeks of treatment with ROR2i in the MLI model of osteoarthritis in mice

(A) Experimental scheme. Four weeks after menisco-ligament injury (MLI) surgery or sham 
surgery to the contralateral leg, mice received bilateral intra-articular injections of ROR2i or control siRNA for four weeks, $\mathrm{n}=5$ (control), 6 (ROR2i). (B) Incapacitance was measured throughout the study. Circles show mean, error bars show 95\% confidence intervals. Mixed effect linear model with pairwise comparisons at the different time points (Tukey correction of P-values for multiple comparisons), $* * \mathrm{P}=0.0053, * \mathrm{P}=0.011$. (C) The area under the curve of incapacitance was calculated starting from day 26. ANOVA with Tukey's HSD post-hoc test, $\mathrm{P}$ $=0.0047$. Box and whiskers plots show all values, line at the median, boxes extend from the $25^{\text {th }}$ to $75^{\text {th }}$ percentiles, error bars span max to min values. (D) Representative images of Safranin O staining of the medial compartment; F, Femur; M, Meniscus; T, Tibia; bars, $200 \mu \mathrm{m}$. (E) Osteoarthritis severity was assessed using the OARSI scoring system. Box and whiskers plots show all values, line at the median, boxes extend from the $25^{\text {th }}$ to $75^{\text {th }}$ percentiles, error bars span max to min values. (F) histomorphometrical analysis of structural integrity and proteoglycan content of the articular cartilage. Two-way ANOVA with Bonferroni's multiple comparison test, $\# \mathrm{P}=0.021, * \mathrm{P}=0.011$. (G) Bone volume fraction $(\mathrm{BV} / \mathrm{TV})$ of medial tibial subchondral plate was measured by $\mu \mathrm{CT}$. (H) Histomorphometrical measurement of medial tibial subchondral bone thickness, (I) osteophyte perimeter and (J) osteophyte area. (F-J) line at mean, standard error of the mean. (K) Weight gain of mice over 4 weeks of treatment with ROR2i, error bars show standard error of the mean. 


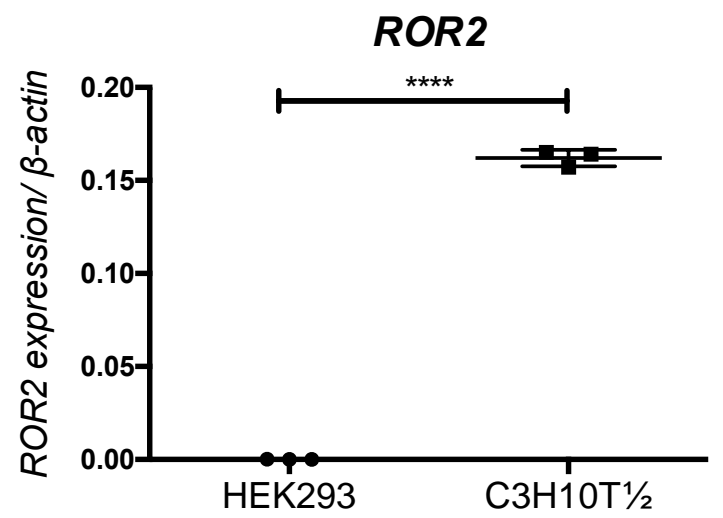

Fig. S8. ROR2 mRNA expression in HEK293 and C3H10T $1 \frac{1}{2}$ cell lines. ROR 2 expression was normalised for $\beta$-actin, $\mathrm{n}=3$, line at mean, standard error of the mean, unpaired $\mathrm{t}$-test, $\mathrm{P}$ $<0.0001$. 

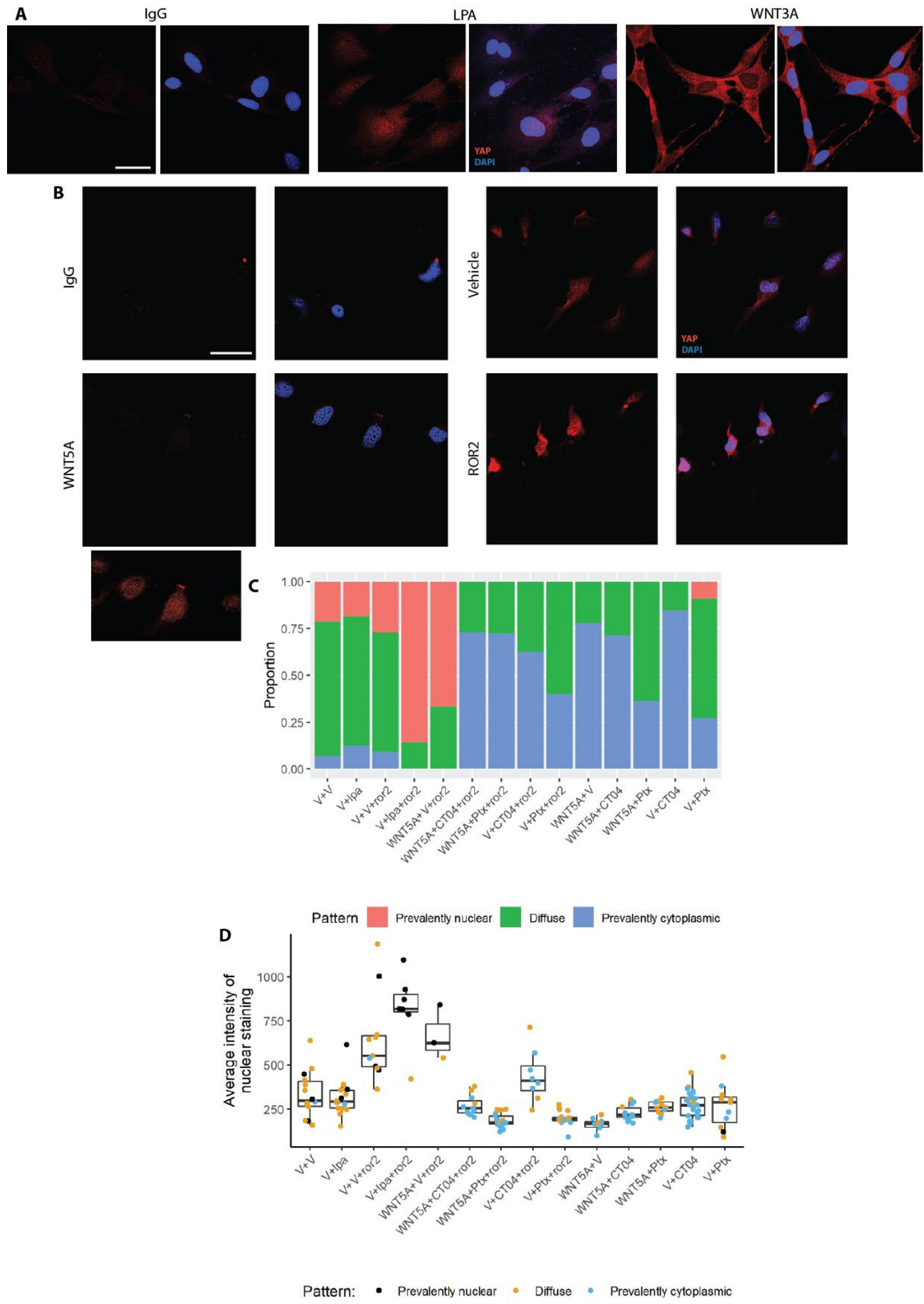

Fig. S9. WNT5A/ROR2 signaling induces nuclear accumulation of YAP in a G-protein and

Rho dependent manner. (A) Immunostaining for YAP (red) in C3H10T1/2 cells: remaining 
conditions from Fig. 6E-F. IgG, non-immune isotype control, dapi (blue), bars, $50 \mu \mathrm{m}$. LPA, lysophosphatidic acid. (B) Immunostaining for YAP (red) in C28I/2 cells: remaining conditions from Fig. 6G-I. IgG, non-immune isotype control, dapi (blue), bars, $50 \mu \mathrm{m}$. Inset shows WNT5A YAP staining amplified to visualise cytoplasmic staining (not used for quantification of intensity). (C) Quantification of the proportion of cells with prevalently nuclear, diffuse or cytoplasmic YAP staining: remaining conditions from Figure 6H. (D) Intensity of YAP staining within the nucleus: remaining conditions from Figure 6I. Box and whiskers plots show all values, line at the median, boxes extend from the $25^{\text {th }}$ to $75^{\text {th }}$ percentiles, error bars span max to min values. 

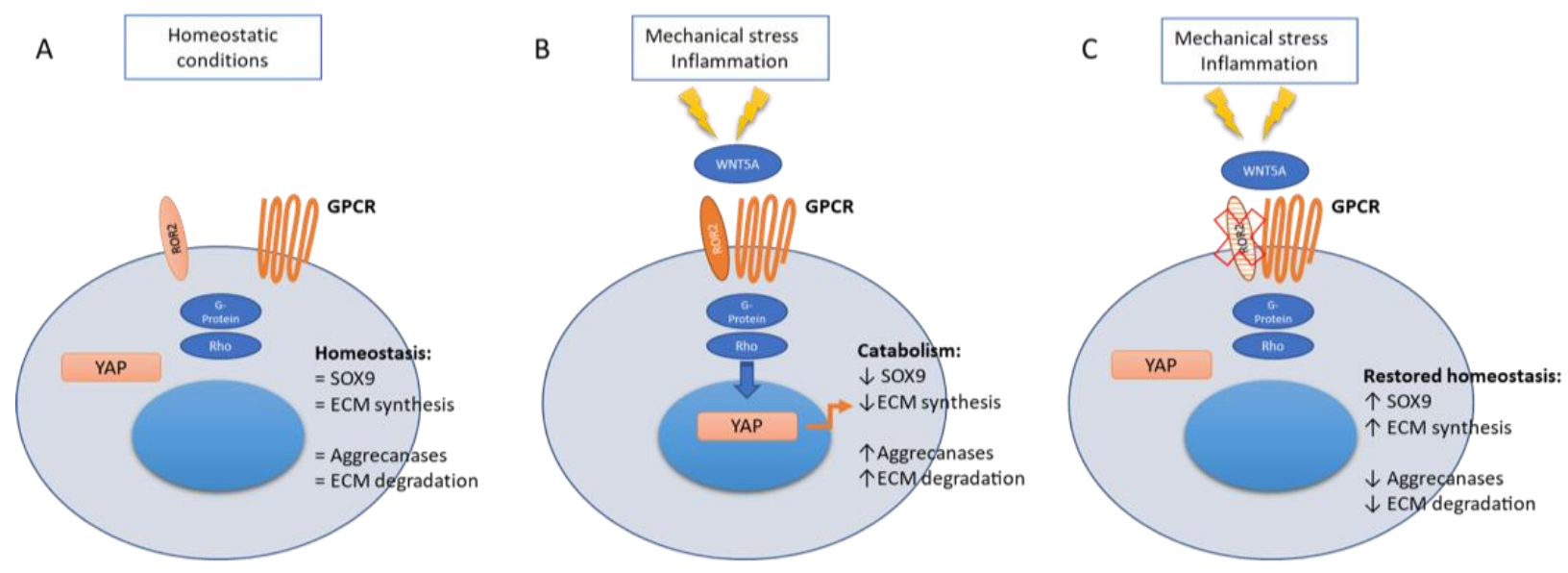

Fig. S10. ROR2 blockade supports cartilage homeostasis by suppressing YAP signaling.

(A) In adulthood, under physiological conditions, ROR2 and WNT5A are expressed in low amounts in the cartilage. (B) Upon cartilage injury, ROR2 and WNTs (including WNT5A) are upregulated. WNT5A activates ROR2 signaling, which, through the co-operation of G-protein coupled receptors (GPCR) and Rho, induce nuclear localization of YAP and activate catabolic signaling. (C) Blocking ROR2 prevents nuclear localization of YAP and restores homeostasis through downregulation of catabolic enzymes and increased proteoglycan production. In the menisco-ligament injury model of osteoarthritis, this ameliorates pain and reduces structural damage to the cartilage. 


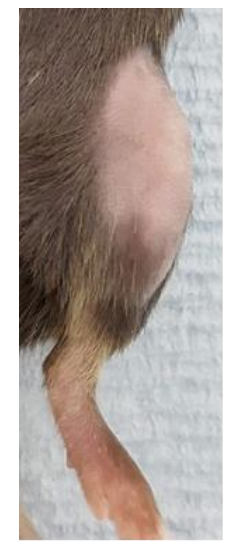

0

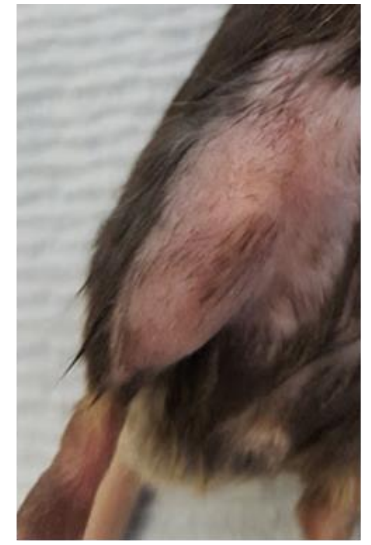

2

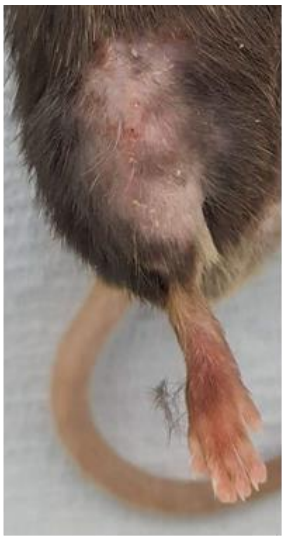

3

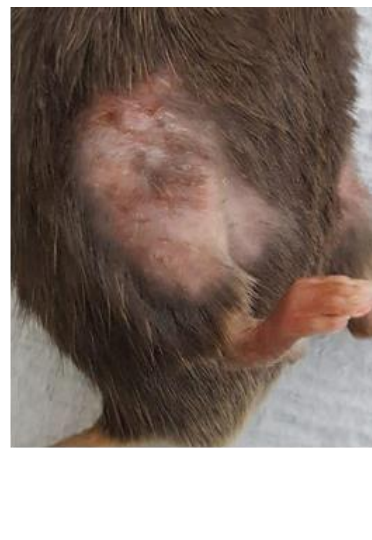

4

Fig. S11. Mouse skin scoring system; $0=$ normal, 2= Mild erythema and skin induration, 3=eczema, 4= severe eczema (See table S3 for more details). 

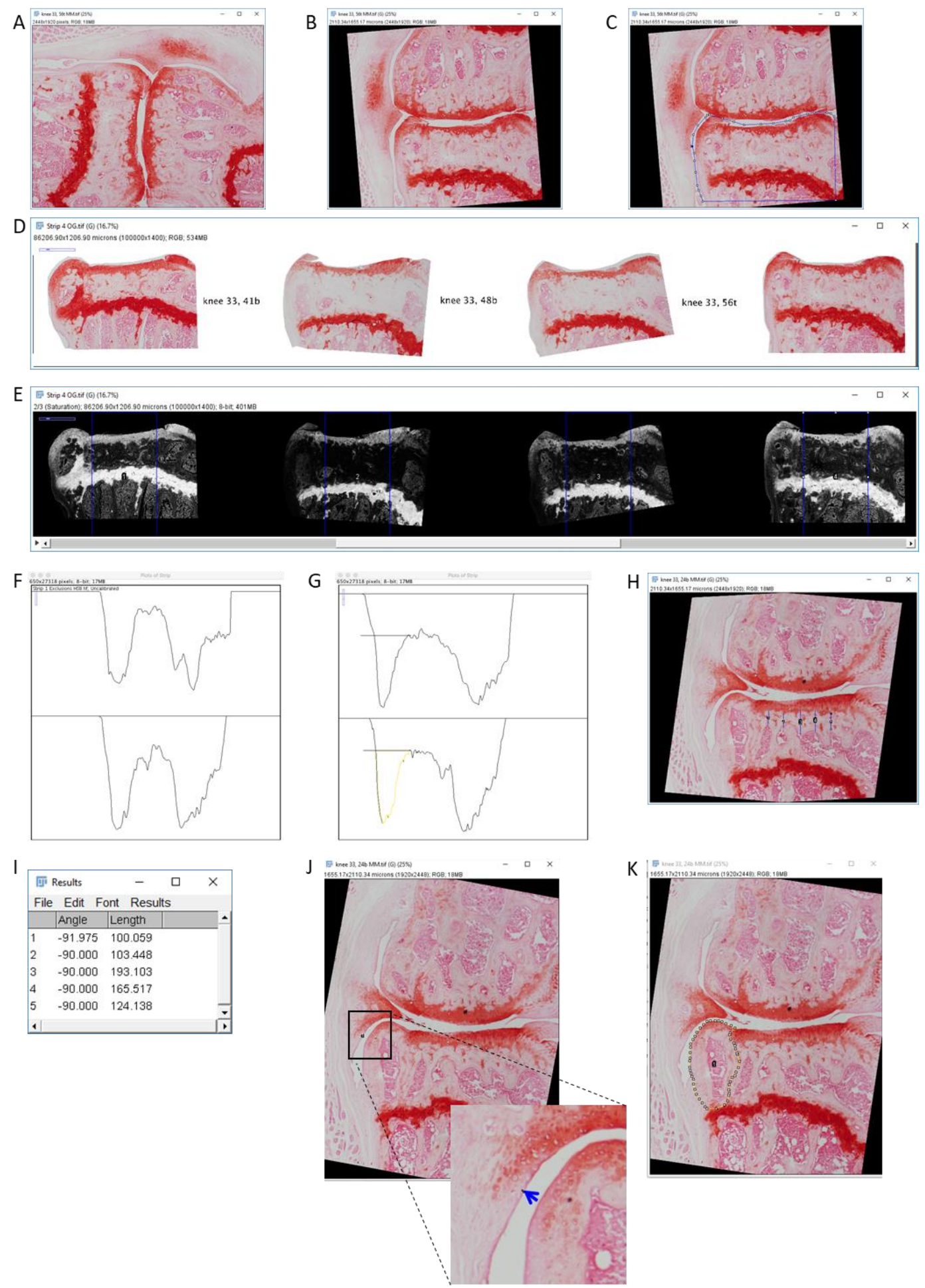

Fig. S12. Histomorphometrical analysis of joint tissues

(A) Each image was opened in ImageJ after setting a global scale and (B) rotated so that a line drawn along the cartilage-bone junction in the middle of the plateau is perfectly horizontal. (C) 
Tibial plateau was selected using a polygon or free-hand tool, (D) all sections were placed on a single large canvas. (E) Saturation stack was used to isolate the metachromatic Safranin O staining and a rectangle 600 microns wide and the full height of the canvas was set as the region of interest. (F) Density profile of each section, (G) limited the articular cartilage peak. (H) Five measurements of the subchondral bone were taken, perpendicular to the cartilage-bone junction to the top of bone marrow, or if there was no bone marrow, to the growth plate, (I) analyse > measure returned the length of the lines. $(\mathbf{J})$ synovial thickness was measured by drawing a line that went horizontally through the synovial lining. Inset shows magnification, blue arrow indicates where the measurement was taken. (K) Medial tibial osteophytes were selected with the polygon or free-hand tool, and area and perimeter were measured. 


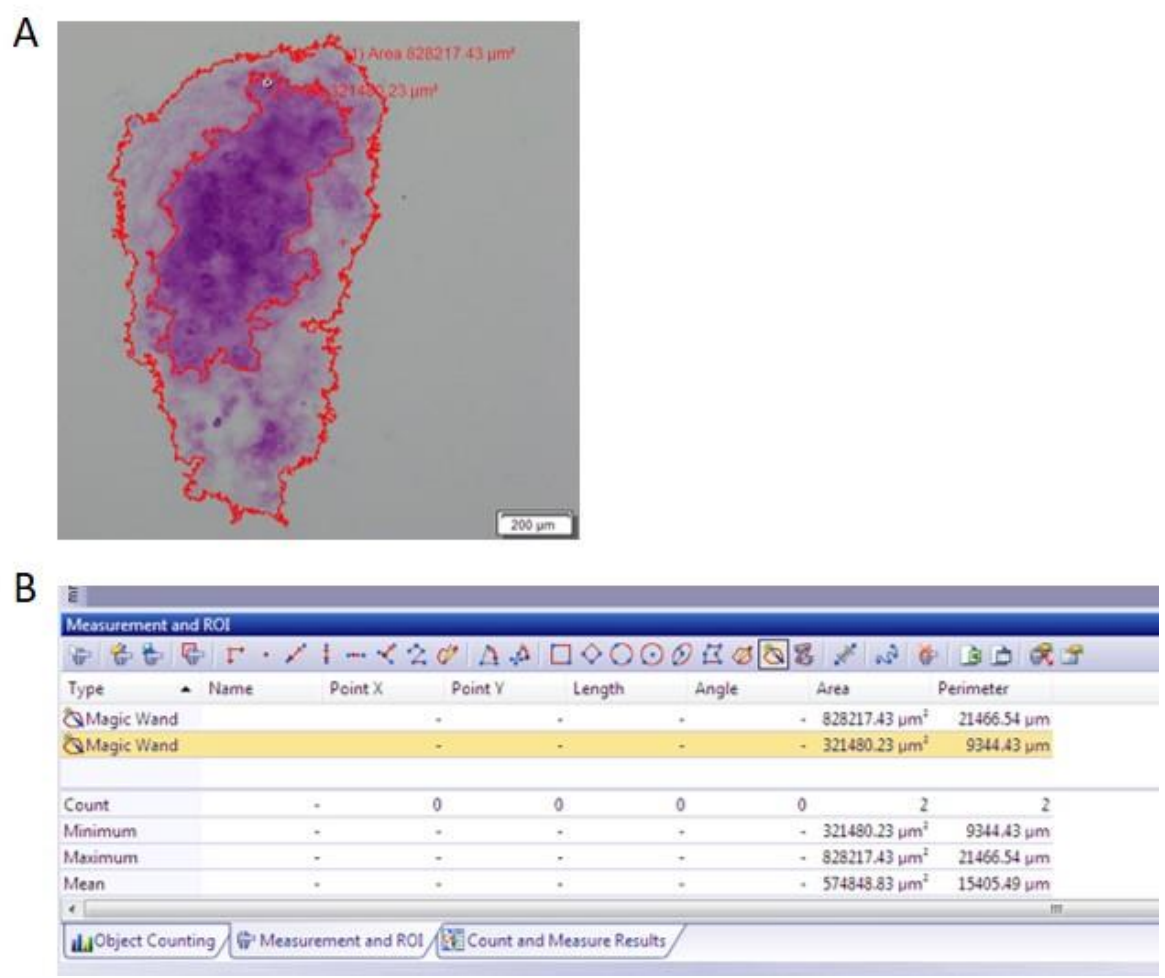

Fig. S13. Toluidine Blue quantification (A) Total area of the explant and differentiated area were selected using the "magic wand" tool of the Cell Sense software (Olympus). (B) Area measurements from Cell Sense were used to calculate \% differentiated area of explants. 
Table S1 Mouse serum analysis following 10 weeks of treatment with control siRNA or ROR2i

\begin{tabular}{|c|c|c|c|}
\hline & Units & Scrambled siRNA \pm SD & ROR2 siRNA \pm SD \\
\hline ALP & $(\mathrm{U} / \mathrm{l})$ & $62 \pm 8.56$ & $60.8 \pm 5.64$ \\
\hline ALT & $(\mathrm{U} / \mathrm{l})$ & $60.2 \pm 58.11$ & $112 \pm 133.38$ \\
\hline AST & $(\mathrm{U} / \mathrm{l})$ & $157.2 \pm 40.03$ & $211 \pm 73.51$ \\
\hline AST/ALT & & $4.053 \pm 1.84$ & $3.800 \pm 2.16$ \\
\hline Total Protein & $(g / l)$ & $58.98 \pm 3.12$ & $58.86 \pm 1.52$ \\
\hline Albumin & $(g / l)$ & $30.48 \pm 1.39$ & $31.28 \pm 1.14$ \\
\hline Total Cholesterol & $(\mathrm{mmol} / \mathrm{l})$ & $3.838 \pm 0.31$ & $4.03 \pm 0.28$ \\
\hline HDL & $(\mathrm{mmol} / \mathrm{l})$ & $2.354 \pm 0.16$ & $2.5 \pm 0.11$ \\
\hline LDL & $(\mathrm{mmol} / \mathrm{l})$ & $0.744 \pm 0.07$ & $0.886 \pm 0.12$ \\
\hline Glucose & $(\mathrm{mmol} / \mathrm{l})$ & $15.306 \pm 2.34$ & $15.7 \pm 1.66$ \\
\hline Triglycerides & $(\mathrm{mmol} / \mathrm{l})$ & $1.434 \pm 0.15$ & $1.898 \pm 0.43$ \\
\hline Total Billirubin & $(\mu \mathrm{mol} / \mathrm{l})$ & $4.76 \pm 0.70$ & $4.02 \pm 0.23$ \\
\hline LDH & $(\mathrm{U} / \mathrm{l})$ & $2109.4 \pm 617.13$ & $1987.8 \pm 892.38$ \\
\hline Amylase & $(\mathrm{U} / \mathrm{l})$ & $659.4 \pm 57.06$ & $1303.4 \pm 1257.10$ \\
\hline CK & (U/l) & $469.8 \pm 126.75$ & $731 \pm 220.08$ \\
\hline Urea & $(\mathrm{mmol} / \mathrm{l})$ & $8.02 \pm 1.02$ & $9.48 \pm 1.14$ \\
\hline Creatinine & $(\mu \mathrm{mol} / \mathrm{l})$ & $10.30 \pm 0.58$ & $11.08 \pm 1.49$ \\
\hline
\end{tabular}

$\mathrm{n}=4$, unpaired t-test, no significant differences. 


\section{Table S2 Skin scoring system}

\begin{tabular}{cl}
\hline Score & Observation \\
\hline 0 & Normal \\
1 & Mild erythema or skin induration \\
2 & Mild erythema and skin induration \\
3 & Eczema \\
4 & Severe eczema \\
5 & Open wound
\end{tabular}


Table S3 Real-time PCR primer sequences

\begin{tabular}{|c|c|c|c|c|}
\hline Gene & Forward Primer & Reverse Primer & $\begin{array}{l}\text { Amplicon } \\
\text { length (bp) }\end{array}$ & $\begin{array}{c}\text { Annealing } \\
\text { temperature }\left({ }^{\circ} \mathrm{C}\right)\end{array}$ \\
\hline Human/ Mouse & TGACGGGGTCACC & CTAGAAGCATTTGC & 661 & $55^{\circ} \mathrm{C}$ \\
\hline$\beta$-actin & $\begin{array}{l}\text { CACACTGTGCCCAT } \\
\text { CTA }\end{array}$ & $\begin{array}{l}\text { GGTGGACGATGGA } \\
\text { GG }\end{array}$ & & \\
\hline Human ROR1 & $\begin{array}{l}\text { TATACCTGCAGCCA } \\
\text { TTGCAC }\end{array}$ & $\begin{array}{l}\text { CCACAAGGCAGGA } \\
\text { TGAATCT }\end{array}$ & 212 & $55^{\circ} \mathrm{C}$ \\
\hline Human ROR2 & $\begin{array}{l}\text { TGGGAATTCAAGG } \\
\text { GAAAGTG }\end{array}$ & $\begin{array}{l}\text { GCCTGTGGGTCTGT } \\
\text { GTGTAA }\end{array}$ & 293 & $55^{\circ} \mathrm{C}$ \\
\hline Human WNT5A & $\begin{array}{l}\text { CAGCAAAAGAGCC } \\
\text { ATGTTCA }\end{array}$ & $\begin{array}{l}\text { ACACAGTGCCAGTC } \\
\text { TCAGGA }\end{array}$ & 123 & $55^{\circ} \mathrm{C}$ \\
\hline Mouse ADAMTS-4 & $\begin{array}{l}\text { GATACAGCGATGT } \\
\text { GGTCACG }\end{array}$ & $\begin{array}{l}\text { GGCGTAAGAACCG } \\
\text { TCAGAAA }\end{array}$ & 119 & $55^{\circ} \mathrm{C}$ \\
\hline Mouse ADAMTS-5 & $\begin{array}{l}\text { TCTCAGAGGCCTTC } \\
\text { TGCATT }\end{array}$ & $\begin{array}{l}\text { CTGCCCATAATTCG } \\
\text { ACTCGT }\end{array}$ & 184 & $55^{\circ} \mathrm{C}$ \\
\hline Mouse Aggrecan & $\begin{array}{l}\text { GAAGAGCCTCGAA } \\
\text { TCACCTG }\end{array}$ & $\begin{array}{l}\text { ATCCTGGGCACATT } \\
\text { ATGGAA }\end{array}$ & 132 & $55^{\circ} \mathrm{C}$ \\
\hline Mouse Col1A1 & $\begin{array}{l}\text { CCAGTACTCTCCGC } \\
\text { TCTTCC }\end{array}$ & $\begin{array}{l}\text { GTTCGTGACCGTGA } \\
\text { CCTTG }\end{array}$ & 156 & $55^{\circ} \mathrm{C}$ \\
\hline Mouse Col2A1 & $\begin{array}{l}\text { CATTGTTGGTCTGC } \\
\text { CTGGTC }\end{array}$ & $\begin{array}{l}\text { TTCTCTCTCTGCCC } \\
\text { TAAGCC }\end{array}$ & 750 & $55^{\circ} \mathrm{C}$ \\
\hline Mouse ColX & $\begin{array}{l}\text { GCAGCATTACGAC } \\
\text { CCAAGAT }\end{array}$ & $\begin{array}{l}\text { CCTGAAGCCTGATC } \\
\text { CAGGTA }\end{array}$ & 177 & $55^{\circ} \mathrm{C}$ \\
\hline Mouse PCNA & $\begin{array}{l}\text { GGCTCCCAAGATT } \\
\text { GAAGATG }\end{array}$ & $\begin{array}{l}\text { CAGAAAAGACCTC } \\
\text { AGGACACG }\end{array}$ & 110 & $68^{\circ} \mathrm{C}$ \\
\hline Mouse Ror1 & $\begin{array}{l}\text { CCCGGAAAAACTA } \\
\text { GAAGGTG }\end{array}$ & $\begin{array}{l}\text { TTTCCTGGCTGGTG } \\
\text { TCTTTC }\end{array}$ & 140 & $55^{\circ} \mathrm{C}$ \\
\hline Mouse Ror2 & $\begin{array}{l}\text { CCTGCGAACGTGTT } \\
\text { CTTTTT }\end{array}$ & $\begin{array}{l}\text { AGGCACTCCCAAGT } \\
\text { GTTCAG }\end{array}$ & 106 & $55^{\circ} \mathrm{C}$ \\
\hline Mouse Sox 2 & $\begin{array}{c}\text { CCAGGAGAACCCC } \\
\text { AAGATGCACAA }\end{array}$ & $\begin{array}{c}\text { TCATGCTGTAGCTG } \\
\text { CCGTTGCTC }\end{array}$ & 341 & $60^{\circ} \mathrm{C}$ \\
\hline Mouse Sox 9 & $\begin{array}{l}\text { TATGTGGATGTGTG } \\
\text { CGTGTG }\end{array}$ & $\begin{array}{l}\text { CCAGCCACAGCAG } \\
\text { TGAGTAA }\end{array}$ & 137 & $55^{\circ} \mathrm{C}$ \\
\hline Mouse Wnt5A & $\begin{array}{l}\text { ACACAACAATGAA } \\
\text { GCAGGCCGTAG }\end{array}$ & $\begin{array}{l}\text { GGAGTTGAAGCGG } \\
\text { CTGTTGACC }\end{array}$ & 220 & $55^{\circ} \mathrm{C}$ \\
\hline
\end{tabular}




\section{Bibliography}

Valverde-Franco, G., Hum, D., Matsuo, K., Lussier, B., Pelletier, J. P., Fahmi, H., ... Martel-Pelletier, J. (2015). The in vivo effect of prophylactic subchondral bone protection of osteoarthritic synovial membrane in bone-specific Ephb4-overexpressing mice. American Journal of Pathology, 185(2), 335-346. https://doi.org/10.1016/j.ajpath.2014.10.004 